\title{
The Role of Exosomes in the Female Reproductive System and Breast Cancers
}

This article was published in the following Dove Press journal: OncoTargets and Therapy

\author{
Yuqi Bai' \\ Jie Guo' \\ Zhongshan Liu' \\ Yunfeng $\mathrm{Li}^{1}$ \\ Shunzi Jin ${ }^{2}$ \\ Tiejun Wang (D) \\ 'Department of Radiation Oncology, The \\ Second Hospital of Jilin University, \\ Changchun, People's Republic of China; \\ ${ }^{2} \mathrm{NHC}$ Key Laboratory of Radiobiology, \\ jilin University, Changchun, People's \\ Republic of China
}

\begin{abstract}
Exosomes are nanoscale extracellular vesicles released by nearly all cell types. Exosomes were originally considered as waste receptacles for discarding unwanted cellular products; however, these organelles are now considered to be important for cell communication by delivering biologically active molecules such as proteins, DNA, non-coding RNA and mRNA. Studies have revealed that exosomes are closely related to several diseases, especially cancers. Exosomes are indispensable for the emergence and progression of tumor. Here, we review the status of research on exosomes in the female reproductive system cancers and breast cancer, focusing on their biological roles in chemical resistance and immune responses, as well as their underlying applications in drug delivery and nanotherapy and as biological markers for tumor diagnosis.
\end{abstract}

Keywords: exosome, microRNA, cancer, biomarker, nanotherapy

\section{Introduction}

Cancers of the female reproductive system, including cervical cancer $(\mathrm{CC})$, ovarian cancer (OC) and endometrial cancer (EC), as well as breast cancer (BC) are significant causes of death among women, and their incidence continues to increase. Despite advances in chemotherapy, radiation therapy and surgery in recent years, there is still a lack of methods for early diagnosis and effective treatment. A better comprehension of the potential molecular mechanisms of carcinogenesis and developments in particular biological markers are therefore needed.

The tumor environment is composed of tumor cells and non-stationary cells with diverse types of endocellular communication mechanisms. ${ }^{1}$ In recent years, more and more research has been conducted on exosomes derived from diverse cancer and non-cancer cells. ${ }^{2}$ Exosomes play a crucial role in establishing intercellular communication and maintaining tumor cell homeostasis. These vesicles shuttle miscellaneous biomolecules to target cells and are released from tumor cells. Therefore, analysis of tumor-derived exosomes may offer useful markers for precise monitoring of cancers. ${ }^{3}$ Tumor-derived exosomes also mediate immune responses and drug resistance in tumors, and can transfer endogenous and exogenous compounds making them good candidates for the delivery of nanotech drugs. Here, we review the progress in our understanding of the use of exosomes for the diagnosis and treatment of female reproductive system cancers and $\mathrm{BC}$.

\section{Biogenesis and Characterization}

Exosomes are the most widely studied of the three major subunits (exosomes, microvesicles, and apoptotic vesicles (ApoEVs) of extracellular vesicles (EVs)
Department of Radiation Oncology, The Second Hospital of Jilin University, No. 218 Ziqiang Street, Changchun 130022 , People's Republic of China

Tel +8619904449098

Email drwangtiejun@yeah.net
OncoTargets and Therapy 2020:13 12567-12586

\section{(c)}

(c) (7) (5) 2020 Bai et al. This work is published and licensed by Dove Medical Press Limited. The full terms of this license are available at https://www.dovepress.com/terms.php you hereby accept the Terms. Non-commercial uses of the work are permitted without any further permission from Dove Medical Press Limited, provided the work is properly attributed. For permission for commercial use of this work, please see paragraphs 4.2 and 5 of our Terms (https://www.dovepress.com/terms.php). 
liberated from mammiferous cells. ${ }^{4,5}$ In addition to these three primary hypotypes, other EVs include membrane particles, exosome-like particles, EVs derived from neutrophils, ${ }^{6}$ EVs from the prostate, ${ }^{7,8}$ migrasomes, ${ }^{9}$ large liposomes ${ }^{10}$ and others. ${ }^{11}$ There are various names for exosomes in the literature: exosomes, oncosomes, dexosomes, exosome-like particles, and membrane blebs. Exosomes originate from the multivesicular body (MVB) and are cup-shaped when viewed under an electron microscope, with a diameter of 50-150 nm. ${ }^{12}$ ApoEVs comprise nucleoprotein histones and DNA, with a diameter of 1000-5000 nm. ${ }^{13}$ Exosomes are produced by all normal and pathological cells and coexist in all body fluids, including plasma, urine, saliva, amniotic fluid, ascites, and cerebrospinal fluid. ${ }^{4}$ Each exosome carries the imprint of the contents of its parent cell, including nucleic acids, proteins, enzymes, lipids, cytokines, and other soluble factors, depending on the cell of origin, environmental conditions, stage of development, epigenetic variations, and biogenesis. ${ }^{13,14}$ Messenger RNA (mRNA), microRNA (miRNA), ribosomal RNA (rRNA), transfer RNA (tRNA), and long non-coding RNA (lncRNA) ${ }^{15}$ have also been identified in exosomes, providing insights into the epigenetic modifications of cells and changes in their biological activity and function. The biogenesis of exosomes differs from that of other EVs. ${ }^{16,17}$ Studies of the maturation of sheep reticular cells in the 1980s revealed that exosomes were generated by intracellular budding (Figure 1) through the plasmalemma to shape endocellular endosomes and achieve cell surface protein expression. $^{16}$ More invasion of endocellular endosomes results in the production of $\mathrm{MVB}$, which contain vesicles with diameters ranging from 40-150nm. Subsequently, the MVB fuses with lysosomes to degrade inclusions, or release their inclusions into the extracellular space accompanied by serosomes, ${ }^{17}$ a process known as exosome biogenesis.

The mechanisms of exosomal biogenesis are highly regulated via respective pathways, ${ }^{18}$ including endosomal sorting complexes required for transport ESCRT-dependent and ESCRT-independent pathways. In the mechanism of ESCRT panniculus rupture, exosome biogenesis requires four multiprotein subcomplexes (ESCRT-0, ESCRT-I, ESCRT-II and ESCRT-III). Inchoate ESCRT composites (ESCRT-0, ESCRT-I, and ESCRT-III) discern the ubiquitinated cargo through their ubiquitin-bonding subgroups to form steady protein composites in the protoplasm. ESCRTIII is then assembled instantly on the nucleosome and undergoes vesicle division. ${ }^{19}$ Recently, it has been shown that a number of assistant elements, such as ATPase, vacuolar protein sort-associated protein (VPS4) and ALG-2 interacting protein X (ALIX), are involved in the mechanism of ESCRT panniculus rupture. ${ }^{19}$ By comparison, the liberation of exosomes via the ESCRT-independent pathway is

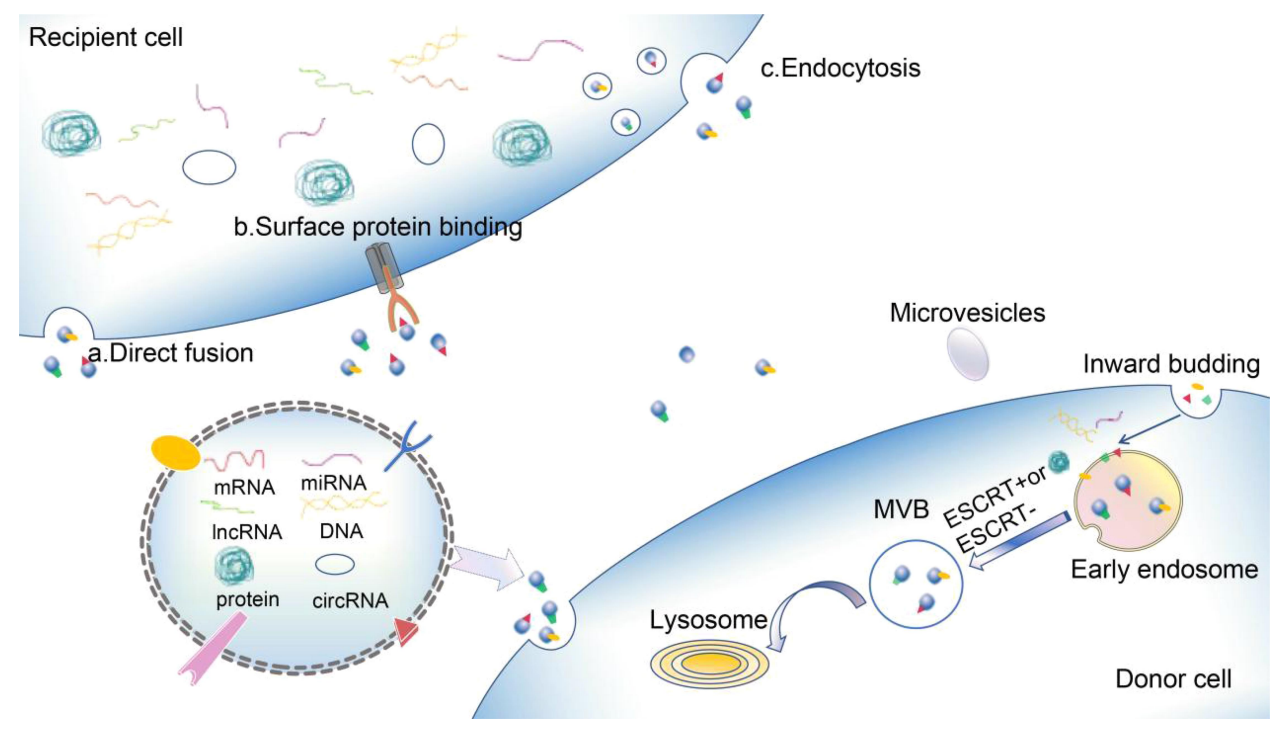

Figure I Biogenesis and content of exosomes.

Notes: Internal germination of the plasmalemma results in the construction of primitive endosomes that bind panniculus proteins. The entrapment of the endosome and encapsulation of the selected cargo (such as nucleic acids and proteins) then leads to the production of MVBs through ESCRT-dependent or ESCRT-independent mechanisms. These MVBs then fuse with the plasmalemma, releasing exosomes to the environment outside the cell. Exosomes transfer the cargos (proteins, mRNAs, miRNAs, IncRNAs, circRNAs, and DNAs) to recipient cells through mechanisms that include a) direct fusion, b) surface protein binding, and c) endocytosis. 
mediated by lipids, like spinolamide, ${ }^{20}$ spinol-1-phosphate, and Rab family proteins, including Rab27a and Rab27b. ${ }^{21}$ Exosomes export many proteins that are promoters or inhibitors of tumors. ${ }^{22}$ For example, the widespread presence of heat shock proteins, $\mathrm{p} 53$, phosphatase, and tension protein homologues in exosomes is closely associated with tumor development. ${ }^{23-26}$ MiRNAs in exosomes account for the majority of circulating miRNAs and have been studied as biomarkers of different cancers. ${ }^{27}$ These discoveries suggest that exosomes are vital in the development of tumors.

\section{The Functions of Exosome-Derived Cargos in Female Reproductive System Cancers and Breast Cancer and Their Underlying Roles as Biomarkers}

Exosomes are pivotal adjusters of cell-cell communication and crucial adjective in the occurrence and development of tumor (Figure 2). Exosomes in cyclic body fluids serve on biomarkers in tumor diagnosis. Exosomes have been discerned in a variety of biosomes, which provides information that allows elucidation of their biogenesis and identification of their cells of origin as well as their biological functions. ${ }^{28}$ Knowledge of exosomes in female reproductive system cancers and $\mathrm{BC}$ is still at a preliminary stage. Here, we discuss various components of exosomes in female reproductive system cancers and $\mathrm{BC}$ as well as other cells in the tumor microenvironment, including exosomal proteins (Table 1), miRNAs (Table 2), lncRNAs, circular RNAs (circRNAs), and DNAs (Table 3).

\section{Exosomal Proteins}

Proteins are the dominating elements of exosomes, and the proteomic profile has attracted increasing attention, especially in the areas of cancer growth and metastasis. Chanteloup et al found that heat shock protein 70 (HSP70) was prominently elevated in adtevak exosomes from BC patients, and circulating HSP70 exosomes were increased in metastatic patients. These observations suggested that HSP70-exosome levels are negatively correlated with response to treatment, and monitoring changes in circulating HSP70-exosome levels may help to predict tumor response and clinical outcomes in $\mathrm{BC} .{ }^{29}$ Mohammed et al detected significantly upregulated exosomal proteins, including heat shock proteins, enolase-1-alpha, S100, and biliverdin reductase $\mathrm{B}$ in the lymph nodes of mice with metastatic $\mathrm{BC}$, demonstrating that these exosomal proteins are involved in regulating tumor cell migration and invasion. ${ }^{30}$ Cen et al verified that platelet-reactive protein 1 (TSP1) was extraordinarily expressed in exosomes derived from $\mathrm{BC}$ cells and demonstrated significantly increased migration of $\mathrm{BC}$ cells in animal models injected with overexpressed TSP1. The results suggested that cancer-derived exosome TSP1 promotes the transendothelial transplantation of $\mathrm{BC}$ cells by destroying the cell-cell wholeness of endothelial cells, thus implicating exosomal TSP1 as a biomarker of BC progression. ${ }^{31}$ Cui et al found that the mRNA expression level of lactate dehydrogenase C4 (LDH-C4) in serum and serum-derived exosomes of BC patients was relatively high. Furthermore, it was discovered that serum and exosomal levels of LDH-C4 were negatively

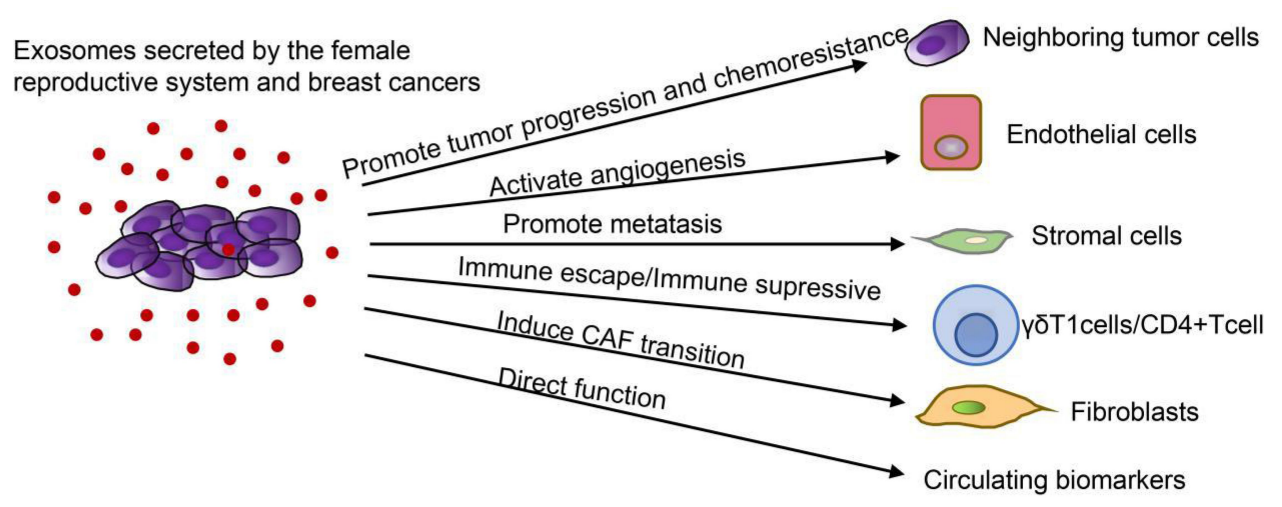

Figure 2 Roles of tumor cells derived exosomes in female reproductive system cancer and breast cancers.

Notes: Exosomes are of great importance in the advancement of tumorigenesis, metastasis, angiogenesis, immune avoidance and drug resistance by the transfer of functional biomolecules. Exosomes from female reproductive system cancers and breast cancers can regulate immunity by inducing immune escape of $\gamma \delta \mathrm{TI}$ cells and immunosuppression of CD4+ T cells. Exosomes from female reproductive system cancers and breast cancers not only transport miRNAs from tumor cells to vascular endothelial cells to facilitate proliferation, invasion, migration and angiogenesis, but also act on tumor stromal cells to produce a beneficial microenvironment for tumor metastasis. Moreover, exosomes secreted by CAF promote EMT, cell propagation, invasion and migration. In addition, proteins, miRNAs, IncRNAs, circRNAs and DNAs in exosomes in circulating body fluids can be used as biomarkers for tumor diagnosis. 
Table I Overview of Exosomal Proteins and Functions in Female Reproductive System Cancer and Breast Cancers

\begin{tabular}{|c|c|c|c|c|c|}
\hline Cancer & Protein & Recipient Cell & Pathway & Function & Reference \\
\hline Breast CA & Heat shock protein 70 (HSP70) & Breast CA cells & $\mathrm{N} / \mathrm{A}$ & Biomaker & [29] \\
\hline Breast CA & $\begin{array}{l}\text { Heat shock protein, enolase I alpha, } \mathrm{SI} 00 \text {, and } \\
\text { biliverdin reductase B }\end{array}$ & Breast CA cells & $\mathrm{N} / \mathrm{A}$ & $\begin{array}{l}\uparrow \text { migration and } \\
\text { invasion }\end{array}$ & [30] \\
\hline Breast CA & Platelet-reactive protein I (TSPI) & Breast CA cells & $\begin{array}{l}\text { Destroying the } \\
\text { intercellular } \\
\text { integrity of } \\
\text { endothelial cells }\end{array}$ & $\uparrow$ migration & [31] \\
\hline Breast CA & Lactate dehydrogenase C4 (LDH-C4) & Breast CA cells & $\mathrm{N} / \mathrm{A}$ & Biomaker & [32] \\
\hline Breast CA & Membrane coupling protein A2 (AnxA2) & Breast CA cells & $\mathrm{N} / \mathrm{A}$ & $\begin{array}{l}\uparrow \text { angiogenesis } \\
\text { and metastasis }\end{array}$ & [33] \\
\hline Breast CA & $\begin{array}{l}\text { Matrix metalloproteinase2 (MMP2) and matrix } \\
\text { metalloproteinase2 (MMP9) }\end{array}$ & Breast CA cells & N/A & $\begin{array}{l}\uparrow p r o l i f e r a t i o n, \\
\text { migration, } \\
\text { invasion and } \\
\text { resistance }\end{array}$ & [107] \\
\hline Ovarian CA & Integrin protein $\alpha 6, \alpha v$, and $\beta$ I & $\begin{array}{l}\text { Epithelial CA } \\
\text { cells }\end{array}$ & N/A & Biomaker & [34] \\
\hline Ovarian CA & CD24 & Ovarian CA cells & $\mathrm{N} / \mathrm{A}$ & Biomaker & [35] \\
\hline Ovarian CA & $\begin{array}{l}\text { Tubulin beta } 3 \text { chain (TUBB3), epithelial cell } \\
\text { surface antigen (EPCAM), claudin } 3 \text { (CLDN3), } \\
\text { proliferating cell nucleus antigen (PCNA) }\end{array}$ & Ovarian CA cells & N/A & Biomaker & [36] \\
\hline Ovarian CA & $\begin{array}{l}\text { v-type collagen } 2 \text { chain (COL5A2) and lipoprotein } \\
\text { lipase (LPL) }\end{array}$ & Ovarian CA cells & $\mathrm{N} / \mathrm{A}$ & Biomaker & [37] \\
\hline Ovarian CA & Small heat shock protein(sHsp) & Ovarian CA cells & $\mathrm{N} / \mathrm{A}$ & Biomaker & {$[100]$} \\
\hline Ovarian CA & Plasma gelsolin (pGSN) & Ovarian CA cells & N/A & $\uparrow$ resistance & {$[113]$} \\
\hline Ovarian CA & DNA methyltransferase I (DNMTI) & Ovarian CA cells & $\begin{array}{l}\text { Stimulating } \\
\text { endogenous } \\
\text { expression }\end{array}$ & $\uparrow$ resistance & [116] \\
\hline Cervical CA & Hh protein & $\begin{array}{l}\text { Cervical CA } \\
\text { cells }\end{array}$ & N/A & Biomarker & [38] \\
\hline
\end{tabular}

correlated with drug therapy, positively correlated with BC recurrence, and negatively correlated with prognosis. This suggested that LDH-C4 derived from serum and exosomes may be an effective indicator for diagnosis of $\mathrm{BC}$, evaluation of treatment efficacy and monitoring $\mathrm{BC}$ recurrence. ${ }^{32}$ Membrane coupling protein A2 (AnxA2) is associated with exosomes and promotes angiogenesis and metastasis. Chaudhary et al found that exo-AnxA2 was highly expressed in the sera of triple negative breast cancer (TNBC) patients and promoted angiogenesis. These findings suggested that exo-AnxA2 represents a potential prognostic factor for TNBC and indicated its value for the development of effective treatment options. ${ }^{33}$ Integrins are vitally important in extracellular matrix attachment and signal conduction, and are involved in cell proliferation and migration. Hurwitz et al found the total levels of exosomal proteins, including integrin proteins $\alpha 6, \alpha v$, and $\beta 1$, is associated with tumor staging in a variety of epithelial cancers. Furthermore, integrin protein $\alpha 6$ largely reflects the expression of breast and ovarian progenitor cells, emphasizing the potential of exosomal integrin protein $\alpha 6$ as a circulating biomarker of $\mathrm{BC}$ and $\mathrm{OC} .{ }^{34}$ Soltesz et al showed that expression of the small molecule cell surface protein, CD24, was higher in exosomes derived from the 
Table 2 Overview of Exosomal miRNAs and Functions in Female Reproductive System Cancer and Breast Cancers

\begin{tabular}{|c|c|c|c|c|c|}
\hline Cancer & miRNA & Recipient Cell & Pathway & Function & Reference \\
\hline Breast CA & miR-1910-3p & Breast CA cells & $N F-k B$ and wnt $/ \beta$-catenin & $\uparrow$ Tumor cell growth & [39] \\
\hline Breast CA & miR-18ID-5p & Breast CA cells & CDX2 and HOXA5 & $\uparrow E M T$ & [40] \\
\hline Breast CA & $\operatorname{miR}-4516$ & Breast CA cells & FOSLI-dependent TNBC & $\begin{array}{l}\uparrow p r o l i f e r a t i o n \text { and } \\
\text { malignancy }\end{array}$ & {$[4 \mid]$} \\
\hline Breast CA & $m i R-3613-3 p$ & Breast CA cells & Targeting the expression of SOCS2 & $\downarrow$ proliferation and metastasis & [42] \\
\hline Breast CA & miR-27a-3p & $\gamma \delta \mathrm{TI}$ cells & $\begin{array}{l}\text { Up-regulating PD-LI through the MAGI2/ } \\
\text { PTEN/PI3K }\end{array}$ & $\uparrow$ immune escape & [86] \\
\hline Breast CA & miR-22I-3p & Breast CA cells & Targeting PIK3RI through the PIJKIAKT & $\uparrow$ resistance & [109] \\
\hline Breast CA & miR-I55 & Breast CA cells & N/A & $\uparrow$ resistance & {$[110]$} \\
\hline Ovarian CA & miR-22I-3p & Ovarian CA cells & Inhibiting CDKN/B & $\uparrow$ progression and $\downarrow$ prognosis & [48] \\
\hline Ovarian CA & miR- $|4|-3 p$ & Endothelial cells & Raising VEGFR-2 expression & $\uparrow m i g r a t i o n$ and angiogenesis & [49] \\
\hline Ovarian CA & $\operatorname{miR}-205$ & Endothelial cells & PTEN-AKT & $\uparrow$ angiogenesis and metastasis & [50] \\
\hline Ovarian CA & $\operatorname{miR2I}$ & Ovarian CA cells & Combinng with APAFI & $\downarrow$ apoptosis & {$[51]$} \\
\hline Ovarian CA & $\begin{array}{l}m i R-29 a-3 p \text { and miR- } \\
2 I-5\end{array}$ & CD4+ T cells & $\begin{array}{l}\text { Suppressing STAT3 and regulating Treg/Th } 17 \\
\text { cells }\end{array}$ & $\uparrow$ progression and metastasis & [94] \\
\hline Ovarian CA & $\begin{array}{l}\text { miR-2I-3p, miR-2I- } \\
5 p \text { and miR-89I-5p }\end{array}$ & Ovarian CA cells & $\begin{array}{l}\text { Upregulating detoxification metabolic } \\
\text { pathways and DNA repair mechanisms }\end{array}$ & $\uparrow$ resistance & [112] \\
\hline Ovarian CA & $\mathrm{miR}-223$ & $\begin{array}{l}\text { Hypoxic } \\
\text { macrophages }\end{array}$ & PTEN-PI3KIAKT & $\uparrow$ resistance & [114] \\
\hline Ovarian CA & miR-1246 & Ovarian CA cells & Targeting Cavl & $\uparrow$ resistance & {$[117]$} \\
\hline Ovarian CA & miR-98-5p & Ovarian CA cells & Inhibiting CDKNIA expression & $\uparrow$ resistance & {$[118]$} \\
\hline Ovarian CA & $m i R-199 a-3 p$ & Ovarian CA cells & Inhibiting the expression of C-Met & $\downarrow$ proliferation and invasion & {$[125]$} \\
\hline Cervical CA & miR-22I-3p & Endothelial cells & Regulating MAPKIO & $\begin{array}{l}\uparrow \text { proliferation, invasion, } \\
\text { migration and angiogenesis }\end{array}$ & [53] \\
\hline Cervical CA & miR-22I-3p & Endothelial cells & Down-regulating THBS2 & $\uparrow$ angiogenesis & [54] \\
\hline Cervical CA & miR-155-5p & Cervical CA cells & $\begin{array}{l}\text { Secreting pro-inflammatory cytokines } \\
\text { (including IL-6 and IL-8) }\end{array}$ & $\uparrow$ malignancy & [55] \\
\hline $\begin{array}{l}\text { Endometrial } \\
\mathrm{CA}\end{array}$ & miR-133a & $\begin{array}{l}\text { Endometrial CA } \\
\text { cells }\end{array}$ & Down-regulating FOXL2 & ^progression & [57] \\
\hline $\begin{array}{l}\text { Endometrial } \\
\mathrm{CA}\end{array}$ & miR-148b & $\begin{array}{l}\text { Endometrial CA } \\
\text { cells }\end{array}$ & $\begin{array}{l}\text { Binding to its downstream target gene } \\
\text { DNMTI }\end{array}$ & $\downarrow$ metastasis & [59] \\
\hline $\begin{array}{l}\text { Endometrial } \\
\mathrm{CA}\end{array}$ & miR-320a & $\begin{array}{l}\text { Endometrial CA } \\
\text { cells }\end{array}$ & $\begin{array}{l}\text { Down-regulating HIFI by miR-320a, leading } \\
\text { to decreased expression of VEGFA }\end{array}$ & $\downarrow$ proliferation & [128] \\
\hline
\end{tabular}

tissues of serous OC patients compared with that in the control group. Furthermore, CD24 was found to be related to FIGO classification, which may be of significance for the diagnosis and monitoring the progression of serous OC. ${ }^{35}$ Liang et al found that many proteins in $\mathrm{OC}$ tissues and secrete have expression, including tubulin beta 3 chain
(TUBB3), epithelial cell surface antigen (EpCAM), claudin 3 (CLDN3) and proliferating cell nucleus antigen (PCNA). These proteins represent potential diagnostic markers and therapeutic targets in OC. ${ }^{36}$ Cheng et al conducted exosomal proteomic and lipidomic analyses in OC and epithelial cells from the surface of the ovary and found that collagen 
Table 3 Overview of Exosomal IncRNAs, circRNAs, DNAs and Functions in Female Reproductive System Cancer and Breast Cancers

\begin{tabular}{|c|c|c|c|c|c|}
\hline Cancer & $\begin{array}{l}\text { IncRNA/ } \\
\text { circRNA/DNA }\end{array}$ & Recipient Cell & Pathway & Function & Reference \\
\hline Breast CA & IncRNA HI9 & Breast CA cells & N/A & Biomarker & [60] \\
\hline Breast CA & InCRNA HOTAIR & Breast CA cells & N/A & $\begin{array}{l}\text { Poor neoadjuvant chemotherapy } \\
\text { and response to tamoxifen } \\
\text { therapy }\end{array}$ & [65] \\
\hline Breast CA & IncRNA SNHGI6 & Breast CA cells & SNHGI6/miR-16-5p/SMAD5/CD73 & Therapy & [90] \\
\hline Breast CA & Inc RNA AFAPI-ASI & Breast CA cells & $\begin{array}{l}\text { Binding to AU binding factor I (AUFI) } \\
\text { and promoting ERBB2 translation }\end{array}$ & $\uparrow$ trastuzumab resistance & [108] \\
\hline Breast CA & IncRNA-SNHGI 4 & Breast CA cells & N/A & $\uparrow$ resistance & {$[111]$} \\
\hline Ovarian CA & IncRNA FALI & Ovarian CA cells & Inhibiting the PTEN/AKT & $\downarrow$ metastasis & [66] \\
\hline Ovarian CA & IncRNA aHIF & Ovarian CA cells & N/A & Biomarker & [67] \\
\hline Ovarian CA & InCRNA MALATI & $\begin{array}{l}\text { Human umbilical } \\
\text { vein endothelial } \\
\text { cells }\end{array}$ & $\begin{array}{l}\text { Affecting angiogenesis(VEGF-A, VEGF-D, } \\
\text { ENA-78, PIGF, IL-8, angiogenin, bFGF and } \\
\text { leptin) }\end{array}$ & $\begin{array}{l}\text { Inhibiting the activity of caspase-3 } \\
\text { and affecting apoptosis-related } \\
\text { proteins }\end{array}$ & [69] \\
\hline Ovarian CA & IncRNA UCAI & Ovarian CA cells & $\begin{array}{l}\text { inhibiting UCAI to promote the } \\
\text { expression of miR- I } 43 \text { and regulate the } \\
\text { expression of FOSL2 }\end{array}$ & $\uparrow$ resistance & {$[115]$} \\
\hline Ovarian CA & circPUMI & $\begin{array}{l}\text { Peritoneal } \\
\text { mesothelial cells }\end{array}$ & $\begin{array}{l}\text { Upregulating the expression of NF-kB } \\
\text { and } M M P 2 \text { by spongizing miR-615-5p } \\
\text { and miR- } 6753-5 p\end{array}$ & $\begin{array}{l}\text { } p \text { roliferation, migration and } \\
\text { invasion }\end{array}$ & [76] \\
\hline Ovarian CA & $w b-m t D N A$ & Ovarian CA cells & N/A & $\uparrow$ progression & [82] \\
\hline Cervical CA & LncRNA-EXOC7 & Cervical CA cells & N/A & $\begin{array}{l}\text { Important biomarkers for } \\
\text { diagnosis, evaluation of efficacy } \\
\text { and detection of recurrence }\end{array}$ & [70] \\
\hline Cervical CA & $\begin{array}{l}\text { IncRNA HOTAIR, } \\
\text { IncRNA MALATI } \\
\text { and IncRNA MEG3 }\end{array}$ & Cervical CA cells & N/A & Biomarker & [7I] \\
\hline Cervical CA & IncRNA TUGI & Cervical CA cells & N/A & $\uparrow$ proliferation and $\downarrow$ apoptosis & [72] \\
\hline Cervical CA & IncRNA TUGI & Cervical CA cells & $\begin{array}{l}\text { Inhibiting the activity of caspase- } 3 \text { and } \\
\text { affecting apoptosis-related proteins }\end{array}$ & †angiogenesis & [73] \\
\hline Cervical CA & $\begin{array}{l}\text { IncRNA HNFIA- } \\
\text { ASI }\end{array}$ & DDP-resistant cells & $\begin{array}{l}\text { Acting as the competitive endogenous } \\
\text { RNA (ceRNA) of miR-34b, promoting } \\
\text { the expression of TUFTI }\end{array}$ & $\uparrow$ resistance & [119] \\
\hline Cervical CA & $\begin{array}{l}\text { hsa-circRNA } \\
-0005795 \text { and hsa- } \\
\text { circRNA-0088088 }\end{array}$ & Cervical CA cells & $\mathrm{N} / \mathrm{A}$ & $\begin{array}{l}\text { improve the diagnosis and } \\
\text { therapy }\end{array}$ & [75] \\
\hline Cervical CA & circEIF4G2 & Cervical CA cells & N/A & biomarker & [77] \\
\hline Cervical CA & ATFI and RAS & Cervical CA cells & N/A & biomarker & [79] \\
\hline
\end{tabular}

type V alpha 2 chain (COL5A2) and lipoprotein lipase (LPL) were expressed at observably higher levels than those in epithelial cells on the surface of the ovary in the exosomes derived from OC cells. This indicated that proteins and lipids from exosomes have important significance in the inchoate diagnosis of OC. ${ }^{37}$ Bhat et al discovered that 
Hh protein was preferentially exported in exosomes of $\mathrm{CC}$ cells, indicating that exosomal $\mathrm{Hh}$ protein may be a potential biomarker of CC. ${ }^{38}$ These findings indicate the value of these proteins as potential biomarkers for prospective diagnosis and prognosis of female reproductive system cancers and $\mathrm{BC}$.

\section{Exosomal microRNAs}

Exosomal miRNAs are critically involved in the initiation, progression, and metastasis of tumors by adjusting the stability of mRNAs or inhibiting their translation. Wang et al demonstrated that exosomal miR-1910-3p facilitated the propagation and transplantation of $\mathrm{BC}$ cells in vivo and vitro. MiR-1910-3p activates the wnt/ $\beta$-catenin and $N F-\kappa B$ signaling pathways by downregulating muscle microtubulin-related protein 3 to promote $\mathrm{BC}$ development. Exosomal serum miR-1910-3p is a valid biomarker accompanied by the conventional biomarker CA153 and can improve the accuracy of BC diagnosis. ${ }^{39}$ Wang et al found that cancer-associated fibroblast (CAF)-derived exosomes containing miR-181D-5p may play a crucial role in the CAF-adjusted $\mathrm{BC}$ tumor environment through $C D X 2$ and $H O X A 5 .^{40}$ Lim et al found that the loss of miR-4516 in CAF-derived exosomes was related to the progression of FOSL1-dependent TNBC, and suggested the potential of miR-4516 as an anticancer drug for TNBC. ${ }^{41}$ Liu et al found that miR-3613-3p was upregulated in CAF exosomes, and the downregulation of exosomal miR-3613$3 \mathrm{p}$ inhibited the propagation and transplantation of $\mathrm{BC}$ cells by targeting SOCS 2 expression, thus implicating miR-3613-3p as a therapeutic target in BC. ${ }^{42}$ Moloney et al showed a significant increase in exosomal miRNA$451 \mathrm{a}$ in the serum of BC patients, suggesting its importance as a potential new biomarker for $\mathrm{BC} .{ }^{43}$ Using RNA sequencing, $\mathrm{Wu}$ et al found higher exosomal levels of miR-150-5p, miR-4665-5p, and miR-576-3p in the miRNA profile of $\mathrm{BC}$ and proposed that these exosomal miRNAs can be used as novel biomarkers with predictive value for $\mathrm{BC}$ recurrence. ${ }^{44} \mathrm{Li}$ et al found that miR-148a in serum exosomes was markedly reduced in BC patients, and downregulation of exosomal miR-148a was closely related to the poor clinical prognosis of $\mathrm{BC}$. These findings suggested that miR-148a in serum exosomes may be a promising diagnostic and prognostic biomarker of BC. ${ }^{45}$ Maeda et al discovered that serum levels of exosomal miR-34a were dramatically increased in patients with early OC compared with those with advanced stage patients. The number of patients with lymph node metastasis was markedly lower and the number of patients in the recurrent disease group was also markedly lower. This demonstrated that serum exosomal miR-34a might be a biomarker that can be used to improve the diagnostic efficiency of OC. ${ }^{46}$ Patients with epithelial ovarian cancer (EOC) are prone to peritoneal metastasis. The main immune cells in the peritoneum are M2 macrophages, especially tumor-associated macrophages (TAMs). ${ }^{47} \mathrm{Li}$ et al analyzed exosome microarrays in EOC and found that exosomal miR-221-3p and miR-221-3p accumulated in M2 macrophages directly inhibited cyclin-dependent kinase inhibitor 1B $(C D K N 1 B)$. Low $C D K N 1 B$ levels were connected with EOC advancement and unfavorable prognosis. This suggested that exosomal miR-221-3p may represent a neoteric biomarker in EOC. ${ }^{48}$ Through studies of exosomes by the EOC cell derived in endothelial cells trigger angiogenesis-related signal events, MasoumiDehghi et al observed that exosomes containing miR141-3p upregulated $V E G F R-2$ expression in endothelial cells, suggesting that EOC cell secretion of exosomal miR-141-3p is an important form of communication between cells and promotes endothelial cell migration and angiogenesis. ${ }^{49}$ In a study of the regulatory effects of exosomal miR-205 on the pTEN-Akt pathway, He et al discovered that exosomal miR-205 was upregulated in OC tissues, and high miR-205 expression was related to the progression of metastasis in OC patients. This suggested that exosomal miR-205 might be a biomarker of OC. ${ }^{50}$ Yeung et al reported that exosomal miR21 extracted from OC-related adipocytes (CAA) and fibroblasts (CAFs) was higher than that in OC cells. It was also shown that miR21 was transferred from CAA or CAF to cancer cells, where it combined with $A P A F 1$, a new target, to inhibit OC cell apoptosis and confer chemical resistance. These data suggested that exosomal miR21 from adjacent stromal cells alters the malignant phenotype of metastatic OC cells. ${ }^{51}$ $\mathrm{Wu}$ et al isolated exosomes from cervical vaginal fluid (CVF) during HPV16 infection, and discovered that hsamiR-5590-3p was significantly downregulated in exosomes from HPV16-infected CVF-derived samples. Studies have shown that hsa-miR-5590-3p serves as a passive adjuster of the $T G F / S M A D$ signaling pathway by downregulating $T G F-R 1$ and $S M A D 4$ transcripts, while the interaction of the $T N F$ and $T G F$ signaling pathways is closely associated with the occurrence of CC. These consequences suggested that exosomal hsa-miR-5590-3p plays a momentous role in the carcinogenesis related to HPV16 infection and may be a useful biomarker for the 
diagnosis of $\mathrm{CC} .{ }^{52}$ Zhang et al found that the exosomal miR-221-3p promoted the proliferation, aggression, transference and angiogenesis of microvascular endothelial cells (MVECs) in CC by accommodating MAPK10, thus implicating miR-221-3p as a diagnostic biomarker of CC. ${ }^{53} \mathrm{Wu}$ et al also detected that exosomal miR-221-3p was transported from tumor cells to vascular endothelial cells in cervical squamous cell carcinoma (CSCC), although their role in promoting angiogenesis was mediated by downregulating THBS2. ${ }^{54}$ These studies demonstrated that exosomal miR-221-3p is a novel biological marker in $\mathrm{CC}$. $\mathrm{Li}$ et al discovered that exosomal miR-155-5p secreted by HIV-infected T cells were immediately targeted in ARID2 deterioration, and miR-155-5p facilitated the advance of $\mathrm{CC}$ by secreting proinflammatory cytokines. This suggested that exosomal miR-155-5p contributes to the malignant advancement of $\mathrm{CC}$, offering underlying biomarkers for prophylaxis and treatment. ${ }^{55}$ Compared with adjacent normal tissues, Zheng et al detected significant differences in the levels of exosomal let-7d-3P and miR-30d-5p in CC tissues, suggesting that they are valuable biological markers for the diagnosis and prediction of CC. ${ }^{56}$ Shi et al found that EC cells secrete exosomes enriched in miR-133a, which downregulates FOXL2 in EC tissues. Further studies proved that EC cellderived exosomes may be absorbed by stromal cells, suggesting that exosomal miRNAs contribute to the development of EC. These results highlighted new areas for the detection and treatment of EC. ${ }^{57}$ Srivastava et al identified hsa-miR-200C-3p the most enriched miRNA in urinederived exosomes of patients with EC. This suggested that differentially expressed miRNAs in exosomes can be used for the discovery of biomarkers and EC diagnosis, and that exosomal hsa-miR-200c-3p represents a noninvasive biological marker for the diagnosis of EC. ${ }^{58} \mathrm{Li}$ et al found that in EC, miR-148b is transferred from CAF to EC cells through exosomes, and that miR-148b inhibits EC metastasis by directly binding to its downstream target gene DNMT1 to mediate its anticancer effects. ${ }^{59}$ In summary, these consequences indicate that exosomal miRNAs not only provide new non-invasive diagnostic methods, but also represent prospective prognostic biomarkers of female reproductive system cancers and BC.

\section{Exosomal IncRNAs and circRNAs}

In addition to miRNAs, exosomes are known to contain several other non-coding RNAs, including lncRNAs and circRNAs, which also play significant regulatory roles in female reproductive system cancers and BC. Exosomes communicate with cells through transporters including lncRNAs, which are considered to represent promising non-invasive biomarkers. Zhong et al found that exosomal lncRNA H19 expression was upregulated in BC patients, and receiver operating characteristic (ROC) analysis revealed the high diagnostic accuracy of exosomal lncRNA H19. ${ }^{60}$ Expression of the $2.2-\mathrm{Kb}$ lncRNA HOTAIR $^{61,62}$ is associated with malignant tumors, including $\mathrm{BC}^{63}$ and $\mathrm{OC}^{64}$ Tang et al demonstrated that HOTAIR in serum exosomes of $\mathrm{BC}$ patients was present at higher level than that in normal individuals. Moreover, this high expression was associated with poor responses to neoadjuvant chemotherapy and tamoxifen, suggesting that serum exosomal HOTAIR may be a biological marker of BC. ${ }^{65}$ Zhang et al found that exosomes secreted by OC cells inhibited the PTEN/AKT signaling pathway through the transfer of lncRNA FAL1, thus inhibiting the metastasis of OC cells both in vitro and in vivo. This may provide a new perspective for an in-depth understanding of the mechanism of $\mathrm{OC}$ and the search for novel targets for targeted molecular therapy. ${ }^{66}$ Tang et al evaluated the expression profile and clinical value of serum exosomal IncRNA antisense hypoxia induction factor $(a H I F)$ in EOC. It was found that EOC patients with high serum exosomal aHIF expression had a poor overall survival, suggesting that exosomal $a H I F$ may be a promising biomarker of poor prognosis. ${ }^{67}$ Metastatic lung adenocarcinoma 1 (MALAT1) is a renowned IncRNA related to tumor angiogenesis and transfer. ${ }^{68}$ Qiu et al demonstrated that MALAT1 was diverted to recipient human umbilical vein endothelial cells (HUVECs) through exosomes, and influenced HUVECs by stimulating the expression of angiogenesis-related genes that ultimately promoted angiogenesis. In addition, circulating exosomal MALAT1 is a prospective serum-based non-invasive biological marker in EOC. ${ }^{69}$ Guo et al found that LncRNA-EXOC7 expression in serum and exosomes was related to the FIGO stage of CC. Treatment and recurrence were correlated by detecting lncRNA-EXOC7 in the serum of patients with $\mathrm{CC}$ and exosomes derived from serum. This suggested that serum and exosomal lncRNAEXOC7 are important biomarkers for diagnosis, evaluation of treatment efficacy and detection of $\mathrm{CC}$ recurrence. ${ }^{70}$ Zhang et al demonstrated differential levels of exosomal HOTAIR, MALAT1 and MEG3 isolated from cervical vaginal lavage of patients with $\mathrm{CC}$ compared with cancer-free volunteers. This suggested that exosomal 
lncRNAs have potential value for inchoate monitoring of $\mathrm{CC}$, and can be used as expedient and noninvasive biological markers. ${ }^{71} T U G 1$ is an lncRNA that promotes the development of $\mathrm{CC}$ by promoting cell proliferation and inhibiting apoptosis. ${ }^{72}$ Lei et al found that exosomal TUG1 in CC promoted HUVEC proliferation by inhibiting caspase-3 activity and regulating the expression of apoptosis-related proteins, indicating that this is the mechanism by which CC cells promote angiogenesis and offering a prospective target for early diagnosis. ${ }^{73}$

The application of circRNAs in exosomes is also of great significance for tumor development. Yang et al detected significant differences in the expression of hsacircRNA-0005795 and hsa-circRNA-0088088 in CC serum exosomes and tissues. ${ }^{74}$ Wang et al also identified other differentially expressed circRNAs from exosomes in BC cells and BC patients, including hsa-circ-0009634, hsa-circ-0020707, hsa-circ-0087213, hsa-circ 0064923, hsa-circ-0104852, hsa-circ-0087064 and hsa-circ $-0126527 .^{75}$ Detection of these circRNAs has been used to improve the diagnosis and treatment of BC. Guan et al investigated the function and potential mechanisms of circPUM1 in OC, found that circPUM1 increased the expression of nuclear factor $\mathrm{B}(N F-\kappa B)$ and $M M P 2$ by sponging miR-615-5p and miR-6753-5p. In-depth studies demonstrated that exosomal circPUM1 acted on peritoneal mesothelial cells and promoted cancer metastasis. These findings suggested that exosomal circPUM1 not only facilitates the propagation, transference and aggression of $\mathrm{OC}$, but also acts on the peritoneum and promotes tumor metastasis. ${ }^{76}$ Mao et al analyzed the circEIF4G2 expression levels and the clinicopathological data of CC patients, and found that circEIF4G2 expression in HeLa cells was dramatically higher than that in primary cervical epithelial cells. This suggested that the increased expression of circEIF4G2 in $\mathrm{CC}$ tissues and serum may be caused by circEIF4G 2 secreted by $\mathrm{CC}$ cell exosomes, and that circEIF4G2 represents a marker for the diagnosis of cervical lesions. ${ }^{77}$

These results indicate that exosomal IncRNAs and circRNAs are also potential biomarkers of female reproductive system cancers and BC.

\section{Exosomal DNAs}

Tumor-derived exosomes frequently carry particular genes that can be tested to monitor tumor progression. ${ }^{78}$ Shi et al discovered that activation transcription factor 1 (ATF1) and $R A S$ genes were markedly upregulated in mouse models of primary and recurrent $\mathrm{CC}$, and were also found in blood exosomes in mouse models. This suggested that exosomal $R A S$ and $A T F 1$ may be latent biological markers for initial diagnosis of CC. ${ }^{79}$ Exosomes may function as a vector for viral DNA. Mata-Rocha et al detected HPV DNA, including the viral oncogene E6/E7, in the exosomes of HeLa cells and cervical samples, suggesting that viral DNA-modified exosomes may be involved in intercellular communication by transmitting oncomolecules to adjacent cells. ${ }^{80}$ Acellular cyclic DNA molecules can be delivered by almost all types of cells, combine with macromolecular compounds or cytomembranes or be internalized by vesicles. ${ }^{81}$ Measurements of the number of mitochondrial DNA copies in whole blood (wb-mtDNA) and adtevak (between cells and exosomal containing mtDNA) in patients with serous epithelial OC showed that the mtDNA copy number was the highest in exosomes, and there were significant differences in wbmtDNA copy numbers between normal controls and patients with early and advanced tumors. This suggested that changes in mtDNA copy number in OC may signal cancer progression, and that wb-mtDNA may even provide information about the emergence of early serous OC. ${ }^{82}$ These studies suggest that exosomal DNA may also be involved in the communication process between tumor cells and could be an underlying biological marker for early diagnosis of female reproductive system cancers and $\mathrm{BC}$.

\section{The Function of Exosomes in the Immune Response of Female Reproductive System Cancers and Breast Cancer}

Tumor cells secrete immunoactive exosomes that inhibit tumor growth via anti-tumor immune responses, ${ }^{83}$ and facilitate the progression of cancer by inhibiting antitumor immunity ${ }^{84}$ or enhancing metastasis. ${ }^{85}$

\section{The Function of Exosomes in the Immune Response of Breast Cancer}

The immune escape of tumor cells is conducive to the etiopathogenesis of BC. Yao et al found that endoplasmic reticulum stress facilitated exosomal excretion and increased exosomal miR-27a-3p expression in BC cells, and miR-27a$3 p$ upregulated $P D-L 1$ via the $M A G I 2 / P T E N / P I 3 K$ axis to promote the immune escape of $\mathrm{BC} .{ }^{86}$ Macrophages play a dual role in the emergence and progression of tumors, 
and can promote and inhibit tumors. ${ }^{87}$ Sen et al showed that macrophage migration increases following exposure to exosomes produced by $\mathrm{BC}$ cells under conditions of high temperature, and the liberation of key chemokines, such as $T N F$ $\alpha$ or RANTES, in turn, may transform the accommodative immune response. This research suggested that exosomes liberated by tumor cells exposed to mild hyperthermia have a potential immunogenic effect. ${ }^{88} \gamma \delta \mathrm{T}$ cells are the main element of tumor-infiltrating lymphocytes (TILs) in BC and are related to poor pathologic features and unfavorable prognostic. ${ }^{89} \mathrm{Ni}$ et al demonstrated that BC-derived exosomes (TDEs) transferred the upregulated $C D 73$ expression of the lncRNA $S N H G 16$ to $\gamma \delta 1$ cells. This was mediated by the enhanced activation of the TGF- $\beta 1 / S M A D 5$ signaling pathway by the BC-derived exosomal $S N H G 16 /$ miR-16$5 \mathrm{p} / S M A D 5$ regulatory axis, thus producing $C D 73$ expression in $\mathrm{V} \delta 1 \mathrm{~T}$ cells. These consequences confirmed the importance of $C D 73+\mathrm{V} \delta 1$ Treg cells in $\mathrm{BC}$ and the potential for future $\mathrm{BC}$ therapy targeting this subgroup or blocking TDE. ${ }^{90}$ By studying the tissue-specific effects of exosomes from highly metastatic $\mathrm{BC}$ cells on immune components, Wen et al determined that $\mathrm{BC}$ exosomes directly inhibited $\mathrm{T}$ cell proliferation and NK cell cytotoxicity, which may inhibit anti-cancer immune responses in pre-metastatic organs. This finding provides novel insights into the tissuespecific outcomes of BC-derived exosomal accumulation and its contribution to immunosuppression and the promotion of metastasis. ${ }^{91} \mathrm{Ham}$ et al found that BC-derived exosomes partially induced $I L-6$ secretion and a pre-survival phenotype in macrophages through glycoprotein 130 (GP130)/STAT3 signaling. These results provide evidence of the role of exosomes in facilitating cargo exchange between $\mathrm{BC}$ and immune cell subsets (Figure 3A). ${ }^{92}$

\section{The Function of Exosomes in the Immune Response of Female Reproductive System Cancers}

The immune microenvironment is also critical for the development of EOC and consists of TAMs and $\mathrm{T}$ lymphocytes, such as regulatory $\mathrm{T}$ cells (Treg) and T helper 17 (Th17) cells. ${ }^{93}$ Zhou et al demonstrated that the Treg/Th17 ratio in both in situ EOC and metastatic peritoneal tissue was markedly higher than that in benign ovarian and peritoneal tumors. Enrichment of miR-29a-3p and miR-21-5 can be found in exosomes derived from TAMs. They regulate the reciprocity between TAMs and $\mathrm{T}$ cells, eliciting the immunosuppressive microenvironment that promotes EOC progression and metastasis. $^{94}$ TAMs are the most common immunerelevant stromal cell in the tumor microenvironment (TME), and the communication between tumor cells and TAMs is involved in the development of EOC. ${ }^{95}$ Chen et al found that exosomes derived from EOC cells promoted remodeling of macrophages into tumor-promoting TAM phenotype. The study revealed that exosomal delivery of miRNAs derived from EOC cells induced M2 macrophage polarization under hypoxic conditions, thereby promoting EOC cell propagation and transplantation. This research suggested that these exosomes and relevant miRNAs may act as potential targets for novel biological markers for EOC. ${ }^{96} \mathrm{Li}$ et al demonstrated that OC cells secrete exosomes to recruit lymphocytes into the tumor microenvironment to inhibit anti-tumor immunity (for example $I L 10$ ) and strengthen cancer aggression, vasculogenesis, and the transmission of proinflammatory cell factors. This suggested that lymphocyte-cancer cell crosstalk through exosomes could contribute to the advancement of valid immunotherapy strategies for OC. ${ }^{97}$ Shenoy et al identified ganglioside $G D 3$ as an inhibitory lipid in exosomes that exist in the ovarian tumor microenvironment, and demonstrated that these exosomes have a causal relationship with the $\mathrm{T}$ cell immunosuppression. Further studies revealed that the inhibitory ability of GD3 was directly associated with sialic acid residues, and targeting $G D 3$ or sialic acid residues is a feasible approach to combating GD3-regulated immunological suppression. ${ }^{98}$ Small heat shock proteins (sHsps) are a group of chaperones that are involved in the pathogenic mechanism of various autoimmune-mediated diseases and cancers. ${ }^{99}$ Wyciszkiewicz et al found that the exosomes from OC patients and EC or endometriosis patients had higher levels of sHsp compared with the levels detected on serum and peritoneal fluid. Furthermore, it was shown that sHsp expression levels were positively correlated with the expression of perforin and granzyme B, which are markers of cytotoxic immune responses. This approach may have broad prospects for the early diagnosis of $\mathrm{OC}$ and exploration of the pathogenesis of autoimmunemediated diseases and cancers. ${ }^{100}$ Dendritic cell (DC)derived exosomes (Dexs) have been revealed to produce specific anti-tumor immune responses both in vitro and vivo. ${ }^{101}$ Chen et al found that poly (I: C) greatly enhanced the effective antineoplastic immunity induced by antigen pulsed Dexs and improved the efficacy of CC. ${ }^{102}$ Ren et al investigated the effect of DCs loaded with HeLa cell- 

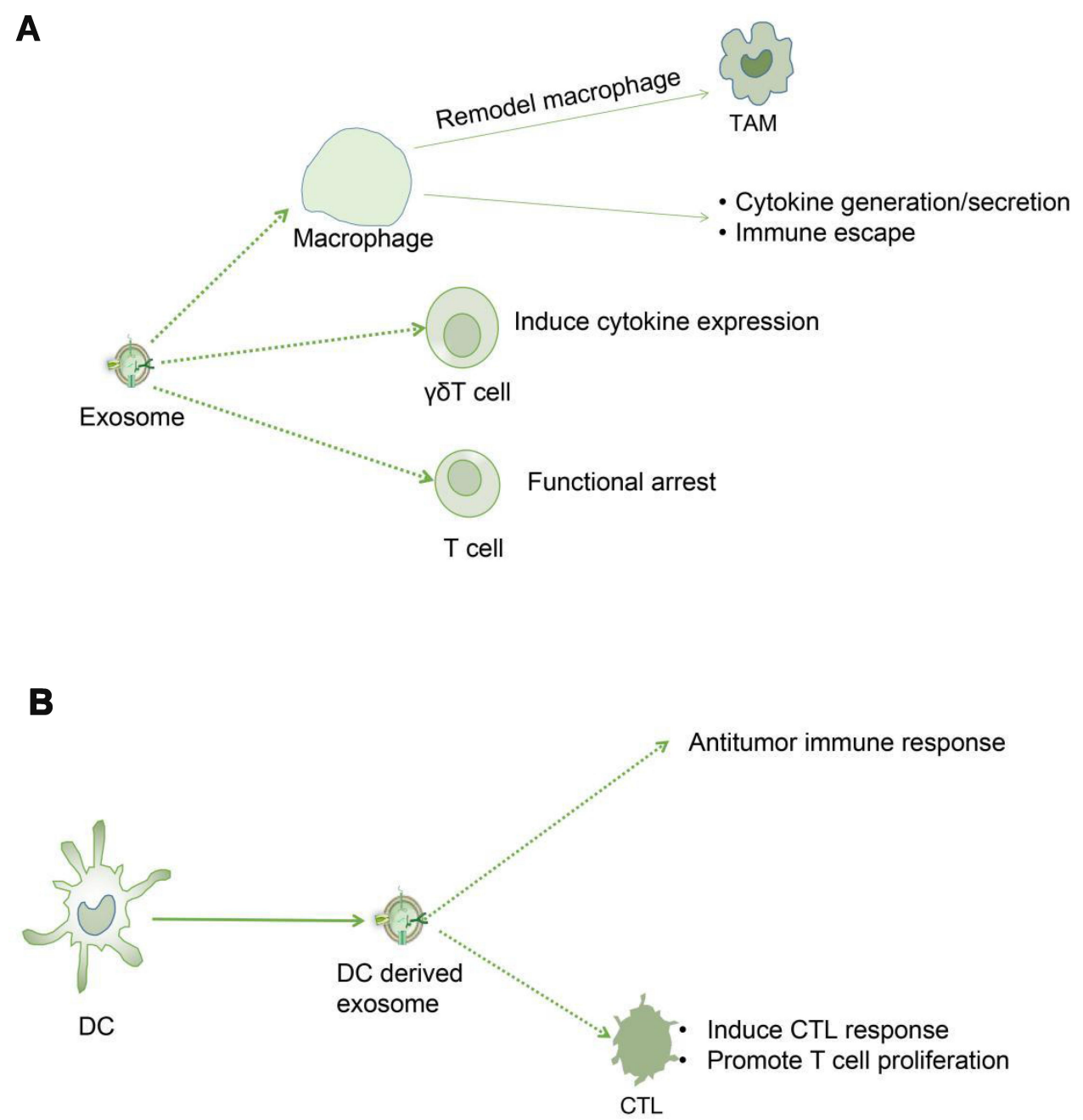

Figure $3(\mathbf{A})$. Tumor cells secrete immunologically active exosomes that act on immune cells (macrophages, $\gamma \delta \mathrm{T}$ cells and T cells) to change tumor immune response and affect tumor growth. (B). Dendritic cells from tumors secrete immunologically active exosomes to change the tumor immune response and affect tumor growth.

derived exosomes (HeLa-exo) on $\mathrm{CC}$ on cytotoxic $\mathrm{T}$ lymphocyte (CTL) responses and the cytotoxic effect of CTLs on HeLa cell lines. It was found that DCs loaded with HeLa-exo promoted $\mathrm{T}$ cell proliferation and induced CTL responses, thereby inhibiting the growth of $\mathrm{CC}$ cells in vitro (Figure 3B). ${ }^{103}$ Epstein-Barr virus $(E B V)$ is a carcinogenic herpes virus associated with a variety of human epithelial and lymphatic malignancies. $E B V$ encoded small RNAs (EBERs) are expressed in large quantities and secreted by exosomes in $E B V$-infected cells. ${ }^{104}$ These transcripts promote innate immune regulation and cell growth. Aromseree et al found that high levels of EBER1 in cervical cells or invasive DC exosomes may play a role in the inflammatory transformation of $H P V$-related CC by modulating innate immune signals. ${ }^{105}$

These studies indicate that exosomes participate in the pathogenesis of tumors by affecting the immune response to tumors, indicating that these exosomes have broad prospects for the diagnosis and immunotherapy of female reproductive system cancers and $\mathrm{BC}$.

\section{Exosomes Induce Drug Resistance in Female Reproductive System Cancers and Breast Cancer Exosomes Induce Drug Resistance in Breast Cancer}

Exosome-mediated drug resistance is a crucial challenge in cancer therapy. Mounting evidence suggests that tumorderived exosomes may transform the extracellular substrate by secreting or activating matrix metalloproteinases (MMPs). ${ }^{106}$ Sadegh-Nejadi et al found that circulating exosomes in the plasma of obese women promoted the propagation, migration and aggression of $\mathrm{BC}$ cells as well as the 
activation of $M M P 2$ and $M M P 9$. Circulating plasma exosomes in obese women may also lead to tamoxifen resistance of $\mathrm{BC}$ cells. ${ }^{107}$ Han et al found that the IncRNA actin filament-associated protein 1 antisense RNA 1 (AFAP1$A S 1)$ is related to trastuzumab resistance. Receptor tyrosine-protein kinase erbB-2 (ERBB2) is one of the most studied oncogenes and is considered a biomarker of BC. It was found that exosomal AFAP1-AS1 induced trastuzumab resistance by binding to $\mathrm{AU}$ binding factor $1(A U F 1)$ and facilitating $E R B B 2$ translation. Consequently, exosomal AFAP1-AS1 levels can be used to predict trastuzumab resistance and treatment efficacy in BC. ${ }^{108}$ Pan et al suggested that miR-221-3p in drug-resistant $\mathrm{BC}$ cell-derived exosomes targets $P I K 3 R 1$ via the $P I 3 K / A K T$ both in vivo and vitro, thereby enhancing $\mathrm{BC}$ cells resistance to adriamycin (ADR) ${ }^{109}$ Santos et al demonstrated miR-155 induction in exosomes isolated from cancer stem cells (CSCs) and drugresistant cells, and also showed that exosomes in $\mathrm{BC}$ cells may mediate resistance and migration to sensitive cells in part through the migration of exosomes containing miR155. This finding confirmed the importance of exosomemediated miR-155 resistance in BC cells. ${ }^{110}$ Dong et al demonstrated that exosomal regulated diversion of IncRNA-SNHG14 induced trastuzumab resistance in BC cells, and that exosome lncRNA-SNHG14in human serum could be considered as an underlying diagnostic biological marker for $\mathrm{BC}$ to improve trastuzumab treatment efficacy. ${ }^{111}$

\section{Exosomes Induce Drug Resistance in Female Reproductive System Cancers}

Alharbi et al studied the role of platinum in heterogeneous populations of $\mathrm{OC}$ cells and their derived exosomes, and found that miR-21-3p, miR-21-5p and miR-891-5p were enriched in exosomes. These exosomal miRNAs could play a role of chemotherapy resistance in $\mathrm{OC}$ by upregulating detoxification metabolic pathways and DNA repair mechanisms. ${ }^{112}$ AsareWerehene et al demonstrated increased expression and secretion of plasma gelsolin (pGSN) in chemotherapy-resistant OC cells compared with the chemically sensitive counterparts. pGSN is secreted and carried by exosomes (ex-pGSN) to upregulate $H I F 1 \alpha$-induced pGSN expression via an autocrine pathway in chemotherapy-resistant OC cells and induces cisplatin resistance in other chemosensitive OC cells. ${ }^{113} \mathrm{Zhu}$ et al found that exosomes derived from anoxic macrophagocytes strengthened the tumorigenic phenotype of EOC cells. Furthermore, under hypoxic conditions, macrophage-derived exosomes rich in miR-223 promoted chemoresistance of EOC cells via $P T E N-P I 3 K / A K T .{ }^{114} \mathrm{Li}$ et al observed that urothelial carcinoma-associated 1 (UCA1) was upregulated in tissues and cell lines of cisplatin-resistant patients, and inhibition of UCA1 promoted miR-143 expression and regulated the expression of FOSL2 in OC to promote cisplatin resistance. ${ }^{115}$ Cao et al demonstrated that DNMT1 counterparts were highly concentrated in exosomes of OC cells, and co-incubation with exosomes promoted endogenetic expression and made host cells resistant to cisplatin cytotoxicity. These results elucidated new mechanisms of cisplatin resistance in $\mathrm{OC}$ foreign secrete DNMT1 and indicated the potential of exosome inhibitors combined with cisplatin in drug-resistant patients. ${ }^{116}$ Kanlikilicer et al found that miR-1246 expression in paclitaxeltolerant $\mathrm{OC}$ exosomes was significantly higher than in the sensitive counterparts, while Cavl gene was the specific target of miR-1246 and participated in the process of exosome transfer. Cavl overexpression and anti-miR-1246 therapy markedly sensitized OC cells to paclitaxel. This research provided a novel therapy to overcome chemical resistance in $\mathrm{OC}$ patients with exosomal miR-1246. ${ }^{117}$ Guo et al showed that CDKN1A was highly expressed in cisplatin sensitive OC cells, and exosomal miR-98-5p targeted CDKN1A to restrain CDKN1A expression. These results suggested that CAFderived exosomes transferred the overexpressed miR-98-5p to facilitate cisplatin resistance in $\mathrm{OC}$ by downregulating $C D K N 1 A .{ }^{118}$ Luo et al found that exosomal lncRNA HNF1A$A S 1$ was upregulated in DDP-resistant (HeLa/DDP) cells, and HNF1A-AS1 acted as a competitive endogenous RNA (ceRNA) of miR-34b, promoting the expression of TUFT1 and consequently promoting DDP resistance in CC cells. ${ }^{119}$

These studies revealed a new mechanism underlying exosome-mediated tumor chemoresistance, and also demonstrated the potential of exosome inhibitors for the treatment of drug-resistant female reproductive system cancers and BC (Figure 4).

\section{The Role of Exosomes for Drug Delivery in Female Reproductive System Cancers and Breast Cancer The Role of Exosomes in Breast Cancer Drug Delivery}

Exosomes have been used to deliver biomolecules and chemotherapeutic drugs for tumor treatment. Han et al successfully isolated exogenous hormones derived from natural killer cells (NK-Exos) by ultra-high speed centrifugation, and prepared a PTX-NK-Exos drug delivery system using NK-Exos 


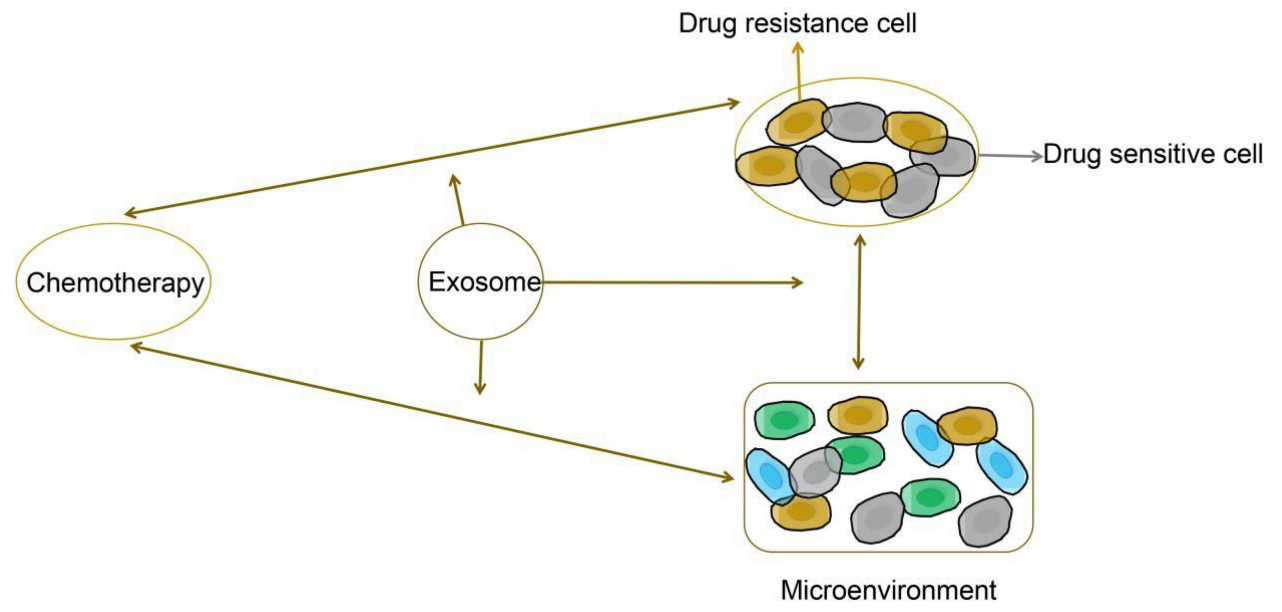

Figure 4 The proposed function of exosomes in the regulation of tumor chemotherapy resistance.

as castor oil-based PTX carrier by electroporation. It was found that PTX-NK-Exos played an anti-tumor role in BC cells by inducing the upregulation of Bax and Caspase-3 in the apoptosis signaling pathway of tumor cells. This finding indicated that exosomes loaded with drugs could effectively inhibit the proliferation and induce tumor cell apoptosis, thus playing an anti-tumor role in BC cells. ${ }^{120}$ Exosomes are the perfect choice for gene targeting on account of their innate non-toxic, nonimmunogenic, ${ }^{121}$ biodegradable and targetable characteristics. Limoni et al adopted the Her2-specific anchor protein repeat protein (DARPins) ${ }^{122}$ developed by Plueckthun to produce Her2-targeted exosomes, which were used to deliver siRNA to Her2-overexpressing BC cells. Studies have shown that targeted exosomes can be successfully loaded with high levels of siRNA and used in Her2-positive BC gene therapy. This approach offers a variety of options for gene therapy and drug delivery. ${ }^{123}$ Exosomes derived from human mesenchymal stroma/stem-like cells (MSCs) have shown significant biocompatibility and reduced innate immunogenicity, thus representing valuable vectors for drug delivery in oncology therapies. Catharina et al found that drug-loaded MSCderived exosomes showed excellent in vitro cytotoxicity by effectively targeting primary and metastatic tumors and reducing side-effects in $\mathrm{BC}$ cell populations and in vivo, offering promising treatment prospects for BC. ${ }^{124}$

\section{The Role of Exosomes in the Female Reproductive System Cancer Drug Delivery}

Kobayashi et al demonstrated that therapy with miR199a3p-loaded-exosomes (miR-199a-3p-Exo) greatly enhanced
miR199a-3p expression in OC cells, and that miR-199a-3pExo suppressed the expression of $C$-Met, the specific target of miR199a-3p, hence inhibiting cell propagation and aggression. These results suggested that exosomes derived from OC patients could be used as a novel drug delivery system (DDS) for prospective targeted molecular therapies. ${ }^{125}$ Liu et al constructed a triptolide-loaded exosome delivery system (TP-Exos) and observed its effect on the propagation and apoptosis of OC cells in vitro and vivo. The results showed that TP-Exos have the normal features of exosomes, as well as exhibiting advanced drug encapsulation efficiency, suggesting that TP-Exos may be a promising treatment strategy for OC. ${ }^{126} \mathrm{Kim}$ et al discovered that tumor cell-derived exosomes act as natural vectors for effective delivery of the CRISPR/Cas9 plasmid to cancer cells. Exosomes loaded with CRISPR/Cas9 inhibited the expression of poly (ADP-ribose) polymerase-1 (PARP$1)$, leading to the induction of OC cell apoptosis. These results suggested the promise of tumor-derived exosomes for drug delivery in tumor therapy. ${ }^{127}$ Zhang et al studied the clinical significance and biological function of miR320 a encapsulated in EVs released by CAFs in EC. The results showed that the miR-320a encapsulated in exosomes secreted by CAF was directly transferred to EC cells, thereby inhibiting their proliferation. This effect which was achieved by miR-320a-induced downregulation of $H I F 1 \alpha$, leading to decreased expression of $V E G F A$ in vitro. These results suggested that CAF-derived EVs overexpressing miR-320a offer a new direction for EC treatment strategies. ${ }^{128}$ These studies suggest that tumorderived exosomes can facilitate drug delivery, which could 
have broad prospects for the therapy of the female reproductive system cancers and $\mathrm{BC}$.

\section{Application of Exosomes in the Nanotherapy of Female Reproductive System Cancers and Breast Cancer Roles of Exosomes as Nanocarriers in Nanotherapy}

In recent years, the application of exosomes in tumor treatment has been extensively studied, and the nanotherapy of exosomes has better research value. Exosomes are endogenous nanoparticles secreted by a variety of cells and have been explored as drug delivery nanocarriers. ${ }^{129,130}$ Zhao et al developed exosome membrane-coated nanoparticles that can protect siRNA from degradation and have excellent biocompatibility. Further studies in vivo showed that exosomal membrane-coated nanoparticles had higher affinity, which significantly inhibited the growth of malignant BC cells. ${ }^{131}$ Tran et al loaded aspirin into exosomes as an anticancer agent, and converted crystalline aspirin into the nano-amorphous form in exosomes with a nano-matrix structure, thereby improving the efficiency of drug encapsulation of exosomes and the dissolution and cytotoxicity of aspirin in BC. Thus, in this study, a novel nano-amorphous exosome delivery system consisting of nanorods was created that can transform anti-inflammatory drugs into effective cancer drugs. ${ }^{132}$ By in vivo adoptive transfer of bone marrow MSCs in CC mice, Naseri et al demonstrated that MSCs-Exo permeate tumor sites and act as an appropriate nanocarriers for the delivery of inhibitory oligonucleotides into neoplastic tissues to downregulate the expression levels of miR-142-3p and miR-150. ${ }^{133}$ Aqil et al found that exosomes containing Anthos exhibited marked anti-proliferative activity against OC cell development and restrained tumor development more effectively compared with the effects of Anthos from berries and carrier controls alone. Anthos has been shown to be effective against $\mathrm{OC}$, and milk exosomes are excellent nanocortors that enhance oral bioavailability of drugs for the treatment of OC. ${ }^{134}$ Aqil et al further demonstrated that exosomal curcumin (ExoCUR) showed stronger antiproliferative and anti-inflammatory activity in $\mathrm{BC}$ and $\mathrm{CC}$ cell lines (as measured by $N F-\kappa B$ activation) compared with free curcumin, suggesting that exosomes are suitable for development as potential nanocarriers to deliver curcumin to improve tissue bioavailability. ${ }^{135}$

\section{Other Roles of Exosomes in Nanotherapy}

Reprogrammed exosomes can be used as nanocontrollers of cellular immunity. Cheng et al found that endogenous exosomes can be used as artificial cellular immune controllers to redirect immune effector cells and regulate their immune reactivity in BC cells. This exosome-based nanoagent provides unique and enhanced pharmacological properties that can be used to develop new therapies for BC. ${ }^{136}$ Endogenous exosome levels may also affect the efficiency of nanoparticles for targeted drug delivery. Wang et al found that pre-treatment with peripheral bloodderived exosomes reduced the deposition grapefruitderived nanovector (GNV) in the liver and improved the treatment efficiency of GNV-carrying drugs in BC mice. ${ }^{137}$ These studies demonstrate the role of exosomes in nanotherapy and open a new chapter in the treatment of female reproductive system cancers and $\mathrm{BC}$.

\section{Clinical Trials of the Use of Exosomes to Treat Female Reproductive System and Breast Cancers}

Several clinical trials have been reported in recent years that further clarify the role of exosomes in the treatment of female reproductive system and breast cancers. Human mesenchymal stem cells (MSCs) have a well-established tumor homing capability, highlighting their potential as a delivery vehicle for targeting tumors. ${ }^{138}$ Makiko et al cocultured BC cells with bone marrow mesenchymal stem cells (BM-MSCs) isolated from human donors. An increase in miR-23b was observed in BM-MSC-derived exosomes, and the miR-23b overexpression induced a dormant phenotype by inhibiting the target gene MARCKS. These findings indicated that the transfer of miRNAs from the bone marrow-derived exosomes of $\mathrm{BC}$ patients may promote the dormancy of breast cancer cells in the metastatic niche to achieve the effective treatment of BC. ${ }^{139}$ Senthilkumar et al isolated exosome simulators (EM) from BM-MSCs in breast cancer patients, mixed the cells with paclitaxel (PTX), and isolated PTX-loaded EM (PTX-MSC-EM), which were found to significantly inhibit the growth of BC. ${ }^{140}$ O'Brien et al found that miR-379 expression was significantly reduced in lymph node 
metastasis compared with $\mathrm{BC}$ tumor tissues from the same patients. MSC-379 secreted by MSC exosomes encapsulates $C O X-2$ as an effective tumor suppressor in $\mathrm{BC}$, showing exciting potential for innovative therapies for metastatic BC. ${ }^{138}$ Musa et al found that conditioned medium (CM) derived from human fat MSC (hAMSC) inhibited OC cells by blocking the cell cycle and activating mitochondria-mediated apoptosis signal transduction. Exosomes derived from hAMSC-CM induced apoptotic signals by upregulating different pro-apoptotic signaling molecules (such as BAX, CASP9 and CASP3) and downregulating the anti-apoptotic protein $B C L 2$. Moreover, exosomal miRNAs are important participants in the inhibitory effect of hAMSC-CM on OC cells. These results will provide new advances in the research and treatment of OC. ${ }^{141} \mathrm{Li}$ et al found that the presence of tumor-specific antigens on exosomes isolated from malignant ascites of ovarian cancer patients could be presented by DC from unrelated cord blood sources, thus inducing tumor-specific cytotoxicity, which may represent a new immunotherapy for OC. ${ }^{142}$ Niko et al also isolated exosomes from the malignant ascites of patients with $\mathrm{OC}$, and showed that the secretion of body in mononuclear precursor cells may also trigger in other immune cells dependence toll-like receptor $(T L R)$ signaling pathway. This process reveals that ovarian cancer and inflammatory diseases are induced through an immunosuppressive mechanism, and that immune therapy of OC is crucial. ${ }^{143}$ These studies suggest that exosomes isolated from MSCs and malignant ascites from cancer patients may have specific inhibitory effects on female reproductive system and breast cancers, and these results will provide new advances in the research and treatment of female reproductive system and breast cancers (Table 4).

\section{Challenges and Future of Exosomes}

Our knowledge of exosomes has grown dramatically in recent years. Exosomes have been shown to be important modulators in tumor biology, and tumor-derived exosomes containing tumor-specific antigens and nucleic acids can be used as potential diagnostic and predictive biomarkers for noninvasive assessment. Exosomes are also used to identify patients who may develop metastatic disease, and the production of exosomes may provide new targets for cancer treatment. The use of exosomes as a carrier of cellular information is a promising strategy in the field of targeted drug delivery in the treatment of cancer, and improved functional exosome mimics have greatly improved drug acceptability in this DDS. However, more efficient and widespread use of exosomes is still problematic. For example, drug delivery systems require nucleic acid drugs to be effectively transfected into exosomes, and host cells suitable for exosome injection pose a challenge for future clinical applications. Appropriate cell selection can also determine the natural population of exosome surface

Table 4 Overview of Clinical Trials of Using Exosomes to Treat Female Reproductive System and Breast Cancers

\begin{tabular}{|l|l|l|l|l|l|l|}
\hline Cancer & Exosome & Donor Cell & Recipient Cell & Pathway & Function & Reference \\
\hline Breast CA & miR-23b & $\begin{array}{l}\text { mesenchymal stem } \\
\text { cells(MSC) }\end{array}$ & Breast CA cells & inhibiting the target gene MARCKS & therapy & {$[$ [139] } \\
\hline Breast CA & $\begin{array}{l}\text { Exosome } \\
\text { mimetics } \\
\text { (EMs) }\end{array}$ & MSC & Breast CA cells & As drug delivery vehicles & Therapy & {$[$ [140] } \\
\hline Breast CA & miR-379 & MSC & Breast CA cells & As drug delivery vehicles & Therapy & [138] \\
\hline Ovarian CA & $\begin{array}{l}\text { Exosome } \\
\text { mimetics } \\
\text { (EMs) }\end{array}$ & $\begin{array}{l}\text { Human fat MSC } \\
\text { (hAMSC) }\end{array}$ & Ovarian CA cells & $\begin{array}{l}\text { blocking cell cycle and activating } \\
\text { mitochondria-mediated apoptosis signal } \\
\text { transduction. }\end{array}$ & Therapy & [14I] \\
\hline Ovarian CA & $\begin{array}{l}\text { Exosomal } \\
\text { proteins }\end{array}$ & $\begin{array}{l}\text { Malignant ascites } \\
\text { of ovarian cancer } \\
\text { patients }\end{array}$ & Ovarian CA cells & Presenting tumor-specific antigens & Therapy & [142] \\
\hline Ovarian CA & $\begin{array}{l}\text { Exosomal } \\
\text { proteins }\end{array}$ & $\begin{array}{l}\text { Malignant ascites } \\
\text { of ovarian cancer } \\
\text { patients }\end{array}$ & Ovarian CA cells & $\begin{array}{l}\text { The knockdown of Toll-like receptor 2 } \\
\text { (TLR2) and TLR4 blocked NF } k B \text { and STAT3 } \\
\text { activation }\end{array}$ & Therapy & [143] \\
\hline
\end{tabular}


proteins, which ensures ideal ligand-receptor interactions with the proposed target cell. Optimization of the producer-target cell combination is critical to the production of exosomes for therapeutic use. Despite these potential drawbacks and reservations, this area of research is highly dynamic and promises to provide novel approaches to the diagnosis and treatment of cancer patients. In addition, the accurate isolation, identification and high-throughput clinical application of EVs face great challenges. The further development of cancer exosome proteomics and the improvement of microfluidics technology to detect exosomes will improve their application in cancer diagnosis.

\section{Conclusion}

The current research on exosomes has reshaped our understanding of exosomes and provided new targets for cancer diagnosis and treatment. In this review, we describe the biogenesis of exosomes and the main mechanisms of exosome-mediated immunity, chemoresistance, and drug delivery. Regarding clinical applications, our review helps to understand the role of exosomes as biomarkers, nanotherapy in female reproductive system cancer and breast cancers, and clinical trials of the use of exosomes. However, it must be pointed out that the key components of exosomes have not been fully clarified, and there is still a long way to go to fully understand the role of exosomes in female reproductive system cancer and breast cancers. More extensive and in-depth research is still needed to fully understand the role of exosomes and to develop exosome-based clinical programs for the diagnosis, prognosis and treatment of female reproductive system cancer and breast cancers in the future.

\section{Funding}

This study was funded by Jilin Province Financial and Health Project(Research on the Differential Expression of Cyclic RNA in Cervical Cancer HeLa Cells and the Mechanism of Radiation Resistance under Radiation Induction); Jilin Provincial Department of Finance (Consortium of Medical Consortium for Diagnosis and Treatment of Difficult Women's Tumors and Precision Radiotherapy Training Base Construction project); Jilin Province Medical and Health Talent Special Project (2019SCZT010).The funders had no role in study design, decision to publish, or preparation of the manuscript.

\section{Disclosure}

The authors report no conflicts of interest in this work.

\section{References}

1. Wang M, Zhao J, Zhang L, et al. Role of tumor microenvironment in tumorigenesis. J Cancer. 2017;8(5):761-773. doi:10.7150/jca.17648

2. Rezaie J, Nejati V, Khaksar M, et al. Diabetic sera disrupted the normal exosome signaling pathway in human mesenchymal stem cells in vitro. Cell Tissue Res. 2018;374(3):555-565. doi:10.1007/ s00441-018-2895-x

3. Sheehan C, D'Souza-Schorey C. Tumor-derived extracellular vesicles: molecular parcels that enable regulation of the immune response in cancer. $J$ Cell Sci. 2019;132(20):jcs235085. doi:10.1242/jcs. 235085

4. Brinton LT, Sloane HS, Kester M, Kelly KA. Formation and role of exosomes in cancer. Cell Mol Life Sci. 2015;72(4):659-671. doi:10.1007/s00018-014-1764-3

5. Cocucci E, Meldolesi J. Ectosomes and exosomes: shedding the confusion between extracellular vesicles. Trends Cell Biol. 2015;25 (6):364-372. doi:10.1016/j.tcb.2015.01.004

6. Gasser O, Hess C, Miot S, Deon C, Sanchez JC, Schifferli JA. Characterisation and properties of ectosomes released by human polymorphonuclear neutrophils. Exp Cell Res. 2003;285 (2):243-257. doi:10.1016/s0014-4827(03)00055-7

7. Ronquist G, Hedström M. Restoration of detergent-inactivated adenosine triphosphatase activity of human prostatic fluid with concanavalin A. Biochim Biophys Acta. 1977;483(2):483-486. doi:10.1016/0005-2744(77)90078-x

8. Ronquist G, Brody I, Gottfries A. An $\mathrm{Mg} 2+$ and $\mathrm{Ca} 2+-$ stimulated adenosine triphosphatase in human prostatic fluid-part II. Andrologia. 1978;10(6):427-433. doi:10.1111/j.1439-0272.1978.tb03064.x

9. Ma L, Li Y, Peng J, et al. Discovery of the migrasome, an organelle mediating release of cytoplasmic contents during cell migration. Cell Res. 2015;25(1):24-38. doi:10.1038/cr.2014.135

10. Al-Nedawi K, Meehan B, Micallef J, et al. Intercellular transfer of the oncogenic receptor EGFRvIII by microvesicles derived from tumour cells. Nat Cell Biol. 2008;10(5):619-624. doi:10.1038/ncb1725

11. Meehan B, Rak J, Di Vizio D. Oncosomes - large and small: what are they, where they came from?. J Extracell Vesicles. 2016;5:33109. doi:10.3402/jev.v5.33109

12. Konoshenko MY, Lekchnov EA, Vlassov AV, Laktionov PP. Isolation of Extracellular Vesicles: general Methodologies and Latest Trends. Biomed Res Int. 2018;2018:8545347. doi:10.1155/ 2018/8545347

13. van der Pol E, Böing AN, Harrison P, Sturk A, Nieuwland R. Classification, functions, and clinical relevance of extracellular vesicles. Pharmacol Rev. 2012;64(3):676-705. doi:10.1124/ pr.112.005983

14. Raposo G, Stoorvogel W. Extracellular vesicles: exosomes, microvesicles, and friends. J Cell Biol. 2013;200(4):373-383. doi:10.1083/jcb.201211138

15. Pefanis E, Wang J, Rothschild G, et al. RNA exosome-regulated long non-coding RNA transcription controls super-enhancer activity. Cell. 2015;161(4):774-789. doi:10.1016/j. cell.2015.04.034

16. Pan BT, Teng K, Wu C, Adam M, Johnstone RM. Electron microscopic evidence for externalization of the transferrin receptor in vesicular form in sheep reticulocytes. J Cell Biol. 1985;101 (3):942-948. doi:10.1083/jcb.101.3.942

17. Harding C, Heuser J, Stahl P. Receptor-mediated endocytosis of transferrin and recycling of the transferrin receptor in rat reticulocytes. J Cell Biol. 1983;97(2):329-339. doi:10.1083/ jcb.97.2.329 
18. Kowal J, Tkach M, Théry C. Biogenesis and secretion of exosomes. Curr Opin Cell Biol. 2014;29:116-125. doi:10.1016/j.ceb.2014.05.004

19. Christ L, Raiborg C, Wenzel EM, Campsteijn C. Cellular Functions and Molecular Mechanisms of the ESCRT Membrane-Scission Machinery. Trends Biochem Sci. 2017;42(1):42-56. doi:10.1016/j. tibs.2016.08.016

20. Trajkovic K, Hsu C, Chiantia S, et al. Ceramide triggers budding of exosome vesicles into multivesicular endosomes. Science. 2008;319(5867):1244-1247. doi:10.1126/science.1153124

21. Ostrowski M, Carmo NB, Krumeich S, et al. Rab27a and Rab27b control different steps of the exosome secretion pathway. Nat Cell Biol. 2010;12(1):19. doi:10.1038/ncb2000

22. Gonzalez-Begne M, Lu B, Han X, et al. Proteomic analysis of human parotid gland exosomes by multidimensional protein identification technology (MudPIT). J Proteome Res. 2009;8 (3):1304-1314. doi:10.1021/pr800658c

23. Mathew A, Bell A, Johnstone RM. Hsp-70 is closely associated with the transferrin receptor in exosomes from maturing reticulocytes. Biochem J. 1995;308(Pt 3):823-830. doi:10.1042/bj3080823

24. Yu X, Harris SL, Levine AJ. The regulation of exosome secretion: a novel function of the p53 protein. Cancer Res. 2006;66 (9):4795-4801. doi:10.1158/0008-5472.CAN-05-4579

25. Putz U, Howitt J, Doan A, et al. The tumor suppressor PTEN is exported in exosomes and has phosphatase activity in recipient cells. Sci Signal. 2012;5(243):ra70. doi:10.1126/scisignal.2003084

26. Lim JW, Mathias RA, Kapp EA, et al. Restoration of full-length APC protein in SW480 colon cancer cells induces exosome-mediated secretion of DKK-4. Electrophoresis. 2012;33 (12):1873-1880. doi:10.1002/elps.201100687

27. Gallo A, Tandon M, Alevizos I, Illei GG. The majority of microRNAs detectable in serum and saliva is concentrated in exosomes. PLoS One. 2012;7(3):e30679. doi:10.1371/journal. pone.0030679

28. Feng W, Dean DC, Hornicek FJ, Shi H, Duan Z. Exosomes promote pre-metastatic niche formation in ovarian cancer. Mol Cancer. 2019;18(1):124. doi:10.1186/s12943-019-1049-4

29. Chanteloup G, Cordonnier M, Isambert N, et al. Monitoring HSP70 exosomes in cancer patients' follow up: a clinical prospective pilot study. J Extracell Vesicles. 2020;9(1):1766192. doi:10.1080/ 20013078.2020.1766192

30. Mohammed SI, Torres-Luquis O, Zhou W, Lanman NA, Espina V. Tumor-Draining Lymph Secretome En Route to the Regional Lymph Node in Breast Cancer Metastasis. Breast Cancer. 2020;12:57-67. doi:10.2147/BCTT.S236168

31. Cen J, Feng L, Ke H, et al. Exosomal Thrombospondin-1 Disrupts the Integrity of Endothelial Intercellular Junctions to Facilitate Breast Cancer Cell Metastasis. Cancers. 2019;11(12):1946. doi:10.3390/cancers11121946

32. Cui Z, Chen Y, Hu M, et al. Diagnostic and prognostic value of the cancer-testis antigen lactate dehydrogenase $\mathrm{C} 4$ in breast cancer. Clin Chim Acta. 2020;503:203-209. doi:10.1016/j.cca.2019.11.032

33. Chaudhary P, Gibbs LD, Maji S, Lewis CM, Suzuki S, Vishwanatha JK. Serum exosomal-annexin A2 is associated with African-American triple-negative breast cancer and promotes angiogenesis. Breast Cancer Res. 2020;22(1):11. doi:10.1186/ s13058-020-1251-8

34. Hurwitz SN, Meckes DG. Extracellular Vesicle Integrins Distinguish Unique Cancers. Proteomes. 2019;7(2):14. doi:10. 3390/proteomes7020014

35. Soltész B, Lukács J, Szilágyi E, et al. Expression of CD24 in plasma, exosome and ovarian tissue samples of serous ovarian cancer patients. J Biotechnol. 2019;298:16-20. doi:10.1016/j. jbiotec.2019.03.018

36. Liang B, Peng $\mathrm{P}$, Chen $\mathrm{S}$, et al. Characterization and proteomic analysis of ovarian cancer-derived exosomes. $J$ Proteomics. 2013;80:171-182. doi:10.1016/j.jprot.2012.12.029
37. Cheng L, Zhang K, Qing Y, et al. Proteomic and lipidomic analysis of exosomes derived from ovarian cancer cells and ovarian surface epithelial cells. J Ovarian Res. 2020;13(1):9. doi:10.1186/s13048-020-0609-y

38. Bhat A, Sharma A, Bharti AC. Upstream Hedgehog signaling components are exported in exosomes of cervical cancer cell lines. Nanomedicine. 2018;13(17):2127-2138. doi:10.2217/nnm-2018-0143

39. Wang B, Mao JH, Wang BY, et al. Exosomal miR-1910-3p promotes proliferation, metastasis, and autophagy of breast cancer cells by targeting MTMR3 and activating the NF- $\kappa \mathrm{B}$ signaling pathway [published online ahead of print, 2020 Jun 9]. Cancer Lett. 2020;489:87-99. doi:10.1016/j.canlet.2020.05.038

40. Wang H, Wei H, Wang J, Li L, Chen A, Li Z. MicroRNA-181d-5pContaining Exosomes Derived from CAFs Promote EMT by Regulating CDX2/HOXA5 in Breast Cancer. Mol Ther Nucleic Acids. 2020;19:654-667. doi:10.1016/j.omtn.2019.11.024

41. Kim JE, Kim BG, Jang Y, Kang S, Lee JH, Cho NH. The stromal loss of miR-4516 promotes the FOSL1-dependent proliferation and malignancy of triple negative breast cancer. Cancer Lett. 2020;469:256-265. doi:10.1016/j.canlet.2019.10.039

42. Liu Y, Yang Y, Du J, Lin D, Li F. MiR-3613-3p from carcinoma-associated fibroblasts exosomes promoted breast cancer cell proliferation and metastasis by regulating SOCS2 expression. IUBMB Life. 2020;72(8):1705-1714. doi:10.1002/iub.2292

43. Moloney BM, Gilligan KE, Joyce DP, et al. Investigating the Potential and Pitfalls of EV-Encapsulated MicroRNAs as Circulating Biomarkers of Breast Cancer. Cells. 2020;9(1):141. doi:10.3390/cells9010141

44. Wu H, Wang Q, Zhong $\mathrm{H}$, et al. Differentially expressed microRNAs in exosomes of patients with breast cancer revealed by next-generation sequencing. Oncol Rep. 2020;43(1):240-250. doi:10.3892/or.2019.7401

45. Li D, Wang J, Ma LJ, et al. Identification of serum exosomal miR-148a as a novel prognostic biomarker for breast cancer. Eur Rev Med Pharmacol Sci. 2020;24(13):7303-7309. doi:10.26355/ eurrev 20200721889

46. Maeda K, Sasaki H, Ueda S, et al. Serum exosomal microRNA-34a as a potential biomarker in epithelial ovarian cancer. J Ovarian Res. 2020;13(1):47. doi:10.1186/s13048-020-00648-1

47. Wang X, Zhao X, Wang K, Wu L, Duan T. Interaction of monocytes/macrophages with ovarian cancer cells promotes angiogenesis in vitro. Cancer Sci. 2013;104(4):516-523. doi:10.1111/cas.12110

48. Li X, Tang M. Exosomes released from M2 macrophages transfer miR-221-3p contributed to EOC progression through targeting CDKN1B [published online ahead of print, 2020 Jun 26]. Cancer Med. 2020. doi:10.1002/cam4.3252

49. Masoumi-Dehghi S, Babashah S, Sadeghizadeh M. microRNA-141-3pcontaining small extracellular vesicles derived from epithelial ovarian cancer cells promote endothelial cell angiogenesis through activating the JAK/STAT3 and NF-кB signaling pathways. J Cell Commun Signal. 2020;14(2):233-244. doi:10.1007/s12079-020-00548-5

50. He L, Zhu W, Chen Q, et al. Ovarian cancer cell-secreted exosomal miR-205 promotes metastasis by inducing angiogenesis. Theranostics. 2019;9(26):8206-8220. doi:10.7150/thno.37455

51. Au Yeung CL, Co NN, Tsuruga T, et al. Exosomal transfer of stroma-derived miR21 confers paclitaxel resistance in ovarian cancer cells through targeting APAF1. Nat Commun. 2016;7:11150. doi: $10.1038 /$ ncomms 11150

52. Wu Y, Wang X, Meng L, et al. Changes of miRNA Expression Profiles from Cervical-Vaginal Fluid-Derived Exosomes in Response to HPV16 Infection. Biomed Res Int. 2020;2020:7046894. doi:10.1155/ 2020/7046894

53. Zhang L, Li H, Yuan M, Li M, Zhang S. Cervical Cancer Cells-Secreted Exosomal microRNA-221-3p Promotes Invasion, Migration and Angiogenesis of Microvascular Endothelial Cells in Cervical Cancer by Down-Regulating MAPK10 Expression. Cancer Manag Res. 2019;11:10307-10319. doi:10.2147/CMAR.S221527 
54. Wu XG, Zhou CF, Zhang YM, et al. Cancer-derived exosomal miR-221-3p promotes angiogenesis by targeting THBS2 in cervical squamous cell carcinoma. Angiogenesis. 2019;22(3):397-410. doi:10.1007/s10456-019-09665-1

55. Li H, Chi X, Li R, Ouyang J. HIV-1-infected cell-derived exosomes promote the growth and progression of cervical cancer. Int $J$ Biol Sci. 2019;15(11):2438-2447. doi:10.7150/ijbs.38146

56. Zheng M, Hou L, Ma Y, et al. Exosomal let-7d-3p and miR-30d-5p as diagnostic biomarkers for non-invasive screening of cervical cancer and its precursors. Mol Cancer. 2019;18(1):76. doi:10. 1186/s12943-019-0999-x

57. Shi S, Tan Q, Feng F, et al. Identification of core genes in the progression of endometrial cancer and cancer cell-derived exosomes by an integrative analysis. Sci Rep. 2020;10(1):9862. doi:10.1038/s41598-020-66872-3

58. Srivastava A, Moxley K, Ruskin R, et al.. Biopsy Screening of Urine-Derived Exosomes for miRNAs as Biomarkers in Endometrial Cancer Patients. AAPS J. 2018;20(5):82. doi:10. 1208/s12248-018-0220-y

59. Li BL, Lu W, Qu JJ, Ye L, Du GQ, Wan XP. Loss of exosomal miR-148b from cancer-associated fibroblasts promotes endometrial cancer cell invasion and cancer metastasis. J Cell Physiol. 2019;234(3):2943-2953. doi:10.1002/jcp.27111

60. Zhong G, Wang K, Li J, Xiao S, Wei W, Liu J. Determination of Serum Exosomal H19 as a Noninvasive Biomarker for Breast Cancer Diagnosis. Onco Targets Ther. 2020;13:2563-2571. doi:10.2147/OTT.S243601

61. Rinn JL, Kertesz M, Wang JK, et al. Functional demarcation of active and silent chromatin domains in human HOX loci by noncoding RNAs. Cell. 2007;129(7):1311-1323. doi:10.1016/j.cell. 2007.05.022

62. Bhan A, Mandal SS. LncRNA HOTAIR: A master regulator of chromatin dynamics and cancer. Biochim Biophys Acta. 2015;1856 (1):151-164. doi:10.1016/j.bbcan.2015.07.001

63. Gupta RA, Shah N, Wang KC, et al. Long non-coding RNA HOTAIR reprograms chromatin state to promote cancer metastasis. Nature. 2010;464(7291):1071-1076. doi:10.1038/nature08975

64. Nakayama I, Shibazaki M, Yashima-Abo A, et al. Loss of HOXD10 expression induced by upregulation of miR-10b accelerates the migration and invasion activities of ovarian cancer cells. Int J Oncol. 2013;43(1):63-71. doi:10.3892/ijo.2013.1935

65. Tang S, Zheng K, Tang Y, Li Z, Zou T, Liu D. Overexpression of serum exosomal HOTAIR is correlated with poor survival and poor response to chemotherapy in breast cancer patients. $J$ Biosci. 2019;44(2):37.

66. Zhang Q, Len TY, Zhang SX, Zhao QH, Yang LH. Exosomes transferring long non-coding RNA FAL1 to regulate ovarian cancer metastasis through the PTEN/AKT signaling pathway. Eur Rev Med Pharmacol Sci. 2020;24(1):43-54. doi:10.26355/eurrev_202 001_19894

67. Tang X, Liu S, Liu Y, et al. Circulating serum exosomal aHIF is a novel prognostic predictor for epithelial ovarian cancer. Onco Targets Ther. 2019;12:7699-7711. doi:10.2147/OTT.S220533

68. Liu D, Zhu Y, Pang J, Weng X, Feng X, Guo Y. Knockdown of long non-coding RNA MALAT1 inhibits growth and motility of human hepatoma cells via modulation of miR-195. J Cell Biochem. 2018;119(2):1368-1380. doi:10.1002/jcb.26297

69. Qiu JJ, Lin XJ, Tang XY, Zheng TT, Lin YY, Hua KQ. Exosomal Metastasis-Associated Lung Adenocarcinoma Transcript 1 Promotes Angiogenesis and Predicts Poor Prognosis in Epithelial Ovarian Cancer. Int J Biol Sci. 2018;14(14):1960-1973. doi:10.7150/ijbs. 28048

70. Guo Y, Wang X, Wang K, He Y. Appraising the Value of Serum and Serum-Derived Exosomal LncRNA-EXOC7 as a Promising Biomarker in Cervical Cancer. Clin Lab. 2020;66(7):10. doi:10. 7754/Clin.Lab.2019.191203
71. Zhang J, Liu SC, Luo XH, et al. Exosomal Long Noncoding RNAs are Differentially Expressed in the Cervicovaginal Lavage Samples of Cervical Cancer Patients. J Clin Lab Anal. 2016;30 (6):1116-1121. doi:10.1002/jcla.21990

72. Hu Y, Sun X, Mao C, et al. Upregulation of long noncoding RNA TUG1 promotes cervical cancer cell proliferation and migration. Cancer Med. 2017;6(2):471-482. doi:10.1002/cam4.994

73. Lei L, Mou Q. Exosomal taurine up-regulated 1 promotes angiogenesis and endothelial cell proliferation in cervical cancer. Cancer Biol Ther. 2020;21(8):717-725. doi:10.1080/15384047.2020.1764318

74. Yang SJ, Wang DD, Zhou SY, et al. Identification of circRNA-miRNA networks for exploring an underlying prognosis strategy for breast cancer. Epigenomics. 2020;12(2):101-125. doi:10.2217/epi-2019-0058

75. Wang J, Zhang Q, Zhou S, et al. Circular RNA expression in exosomes derived from breast cancer cells and patients. Epigenomics. 2019;11(4):411-421. doi:10.2217/epi-2018-0111

76. Guan X, Zong ZH, Liu Y, Chen S, Wang LL, Zhao Y. circPUM1 Promotes Tumorigenesis and Progression of Ovarian Cancer by Sponging miR-615-5p and miR-6753-5p. Mol Ther Nucleic Acids. 2019;18:882-892. doi:10.1016/j.omtn.2019.09.032

77. Mao Y, Zhang L, Li Y. Application of CircEIF4G2 in Screening of Cervical Lesions. Clin Lab. 2020;66(6):10. doi:10.7754/Clin. Lab.2019.190915

78. Whiteside TL, Exosomes T-D. Their Role in Cancer Progression. Adv Clin Chem. 2016;74:103-141. doi:10.1016/bs.acc.2015.12.005

79. Shi Y, Wang W, Yang B, Tian H. ATF1 and RAS in exosomes are potential clinical diagnostic markers for cervical cancer. Cell Biochem Funct. 2017;35(7):477-483. doi:10.1002/cbf.3307

80. Guenat D, Hermetet F, Prétet JL, Exosomes MC. Other Extracellular Vesicles in HPV Transmission and Carcinogenesis. Viruses. 2017;9(8):211. doi:10.3390/v9080211

81. Thierry AR, El Messaoudi S, Gahan PB, Anker P, Stroun M. Origins, structures, and functions of circulating DNA in oncology. Cancer Metastasis Rev. 2016;35(3):347-376. doi:10.1007/s10555016-9629-x

82. Keserủ JS, Soltész B, Lukács J, et al. Detection of cell-free, exosomal and whole blood mitochondrial DNA copy number in plasma or whole blood of patients with serous epithelial ovarian cancer. J Biotechnol. 2019;298:76-81. doi:10.1016/j.jbiotec.2019. 04.015

83. Zeelenberg IS, Ostrowski M, Krumeich S, et al. Targeting tumor antigens to secreted membrane vesicles in vivo induces efficient antitumor immune responses. Cancer Res. 2008;68(4):1228-1235. doi:10.1158/0008-5472.CAN-07-3163

84. Jang JY, Lee JK, Jeon YK, Kim CW. Exosome derived from epigallocatechin gallate treated breast cancer cells suppresses tumor growth by inhibiting tumor-associated macrophage infiltration and M2 polarization. BMC Cancer. 2013;13:421. doi:10.1186/ 1471-2407-13-421

85. Ekström EJ, Bergenfelz C, von Bülow V, et al. WNT5A induces release of exosomes containing pro-angiogenic and immunosuppressive factors from malignant melanoma cells. Mol Cancer. 2014;13:88. doi:10.1186/1476-4598-13-88

86. Yao X, Tu Y, Xu Y, Guo Y, Yao F, Zhang X. Endoplasmic reticulum stress-induced exosomal miR-27a-3p promotes immune escape in breast cancer via regulating PD-L1 expression in macrophages [published online ahead of print, $2020 \mathrm{Jul}$ 16]. J Cell Mol Med. 2020. doi: $10.1111 / \mathrm{jcmm} .15367$

87. Siegel RL, Miller KD, Jemal A. Cancer statistics, 2019. CA Cancer J Clin. 2019;69(1):7-34. doi:10.3322/caac.21551

88. Sen K, Sheppe AEF, Singh I, Hui WW, Edelmann MJ, Rinaldi C. Exosomes released by breast cancer cells under mild hyperthermic stress possess immunogenic potential and modulate polarization in vitro in macrophages. Int J Hyperthermia. 2020;37(1):696-710. doi: $10.1080 / 02656736.2020 .1778800$ 
89. Peng G, Wang HY, Peng W, Kiniwa Y, Seo KH, Wang RF. Tumorinfiltrating gammadelta $\mathrm{T}$ cells suppress $\mathrm{T}$ and dendritic cell function via mechanisms controlled by a unique toll-like receptor signaling pathway. Immunity. 2007;27(2):334-348. doi:10.1016/j.immuni. 2007.05.020

90. Ni C, Fang QQ, Chen WZ, et al. Breast cancer-derived exosomes transmit lncRNA SNHG16 to induce CD $73+\gamma \delta 1$ Treg cells. Signal Transduct Target Ther. 2020;5(1):41. doi:10.1038/s41392-0200129-7

91. Wen SW, Sceneay J, Lima LG, et al. The Biodistribution and Immune Suppressive Effects of Breast Cancer-Derived Exosomes. Cancer Res. 2016;76(23):6816-6827. doi:10.1158/0008-5472.CAN-16-0868

92. Ham S, Lima LG, Chai EPZ, et al. Breast Cancer-Derived Exosomes Alter Macrophage Polarization via gp130/STAT3 Signaling. Front Immunol. 2018;9:871. doi:10.3389/fimmu.2018.00871

93. Li S, Li Y, Qu X, Liu X, Liang J. Detection and significance of TregFoxP3(+) and Th17 cells in peripheral blood of non-small cell lung cancer patients. Arch Med Sci. 2014;10(2):232-239. doi:10.5114/aoms.2014.42573

94. Zhou J, Li X, Wu X, et al. Exosomes Released from Tumor-Associated Macrophages Transfer miRNAs That Induce a Treg/Th17 Cell Imbalance in Epithelial Ovarian Cancer. Cancer Immunol Res. 2018;6 (12):1578-1592. doi:10.1158/2326-6066.CIR-17-0479

95. Yin M, Li X, Tan S, et al. Tumor-associated macrophages drive spheroid formation during early transcoelomic metastasis of ovarian cancer. J Clin Invest. 2016;126(11):4157-4173. doi:10.1172/JCI87252

96. Chen X, Zhou J, Li X, Wang X, Lin Y, Wang X. Exosomes derived from hypoxic epithelial ovarian cancer cells deliver microRNAs to macrophages and elicit a tumor-promoted phenotype. Cancer Lett. 2018;435:80-91. doi:10.1016/j.canlet.2018.08.001

97. Li Y, Yang Y, Xiong A, et al. Comparative Gene Expression Analysis of Lymphocytes Treated with Exosomes Derived from Ovarian Cancer and Ovarian Cysts. Front Immunol. 2017;8:607. doi:10.3389/fimmu.2017.00607

98. Shenoy GN, Loyall J, Berenson CS, et al. Sialic Acid-Dependent Inhibition of T Cells by Exosomal Ganglioside GD3 in Ovarian Tumor Microenvironments. J Immunol. 2018;201(12):3750-3758. doi:10.4049/jimmunol.1801041

99. Banerjee S, Lin C-FL, Skinner KA, et al. Heat shock protein 27 differentiates tolerogenic macrophages that may support human breast cancer progression. Cancer Res. 2011;71(2):318-327. doi:10.1158/0008-5472.CAN-10-1778

100. Wyciszkiewicz A, Kalinowska-Łyszczarz A, Nowakowski B, Kaźmierczak K, Osztynowicz K, Michalak S. Expression of small heat shock proteins in exosomes from patients with gynecologic cancers. Sci Rep. 2019;9(1):9817. doi:10.1038/s41598-019-46221-9

101. Bu N, Wu H, Zhang G, et al. Exosomes from Dendritic Cells Loaded with Chaperone-Rich Cell Lysates Elicit a Potent T Cell Immune Response Against Intracranial Glioma in Mice. $J$ Mol Neurosci. 2015;56(3):631-643. doi:10.1007/s12031-015-0506-9

102. Chen S, Lv M, Fang S, Ye W, Gao Y, Xu Y. Poly(I:C) enhanced anti-cervical cancer immunities induced by dendritic cells-derived exosomes. Int J Biol Macromol. 2018;113:1182-1187. doi:10.1016/ j.ijbiomac.2018.02.034

103. Ren G, Wang Y, Yuan S, Wang B. Dendritic cells loaded with HeLa-derived exosomes simulate an antitumor immune response. Oncol Lett. 2018;15(5):6636-6640. doi:10.3892/ol.2018.8126

104. Ahmed W, Philip PS, Tariq S, Khan G, Busson P. Epstein-Barr virus-encoded small RNAs (EBERs) are present in fractions related to exosomes released by EBV-transformed cells. PLoS One. 2014;9 (6):e99163. doi:10.1371/journal.pone.0099163

105. Aromseree S, Middeldorp JM, Pientong C, et al. High Levels of EBV-Encoded RNA 1 (EBER1) Trigger Interferon and Inflammation-Related Genes in Keratinocytes Expressing HPV16 E6/ E7. PLoS One. 2017;12(1):e0169290. doi:10.1371/journal.pone.016 9290
106. Wang J, Wu Y, Guo J, Fei X, Yu L, Ma S. Adipocyte-derived exosomes promote lung cancer metastasis by increasing MMP9 activity via transferring MMP3 to lung cancer cells. Oncotarget. 2017;8(47):81880-81891. doi:10.18632/oncotarget.18737

107. Sadegh-Nejadi S, Afrisham R, Emamgholipour S, et al. Influence of plasma circulating exosomes obtained from obese women on tumorigenesis and tamoxifen resistance in MCF-7 cells [published online ahead of print, 2020 Jun 15]. IUBMB Life. 2020;10:1002.

108. Han M, Gu Y, Lu P, et al. Exosome-mediated lncRNA AFAP1-AS1 promotes trastuzumab resistance through binding with AUF1 and activating ERBB2 translation. Mol Cancer. 2020;19(1):26. doi:10.1186/s12943-020-1145-5

109. Pan X, Hong X, Lai J, et al. Exosomal MicroRNA-221-3p Confers Adriamycin Resistance in Breast Cancer Cells by Targeting PIK3R1. Front Oncol. 2020;10:441. doi:10.3389/fonc.2020.00441

110. Santos JC, Lima NDS, Sarian LO, Matheu A, Ribeiro ML, Derchain SFM. Exosome-mediated breast cancer chemoresistance via miR-155 transfer. Sci Rep. 2018;8(1):829. doi:10.1038/s41598018-19339-5

111. Dong H, Wang W, Chen R, et al. Exosome-mediated transfer of IncRNA-SNHG14 promotes trastuzumab chemoresistance in breast cancer. Int J Oncol. 2018;53(3):1013-1026. doi:10.3892/ijo.2018.4467

112. Alharbi M, Sharma S, Guanzon D, et al. miRNa signature in small extracellular vesicles and their association with platinum resistance and cancer recurrence in ovarian cancer [published online ahead of print, 2020 Apr 23]. Nanomedicine. 2020;28:102207. doi:10.1016/ j.nano.2020.102207

113. Asare-Werehene $M$, Nakka $K$, Reunov $A$, et al. The exosome-mediated autocrine and paracrine actions of plasma gelsolin in ovarian cancer chemoresistance. Oncogene. 2020;39 (7):1600-1616. doi:10.1038/s41388-019-1087-9

114. Zhu X, Shen H, Yin X, et al. Macrophages derived exosomes deliver miR-223 to epithelial ovarian cancer cells to elicit a chemoresistant phenotype. J Exp Clin Cancer Res. 2019;38 (1):81. doi:10.1186/s13046-019-1095-1

115. Li Z, Niu H, Qin Q, et al. IncRNA UCA1 Mediates Resistance to Cisplatin by Regulating the miR-143/FOSL2-Signaling Pathway in Ovarian Cancer. Mol Ther Nucleic Acids. 2019;17:92-101. doi:10.1016/j.omtn.2019.05.007

116. Cao Y-L, Zhuang T, Xing B-H, Li N, Li LQ. Exosomal DNMT1 mediates cisplatin resistance in ovarian cancer. Cell Biochem Funct. 2017;35(6):296-303. doi:10.1002/cbf.3276

117. Kanlikilicer P, Bayraktar R, Denizli M, et al. Exosomal miRNA confers chemo resistance via targeting Cav1/p-gp/M2-type macrophage axis in ovarian cancer [published correction appears in EBioMedicine. 2020 Feb;52:102630]. EBioMedicine. 2018;38:100-112. doi:10.1016/j. ebiom.2018.11.004

118. Guo H, Ha C, Dong H, Yang Z, Ma Y, Ding Y. Cancer-associated fibroblast-derived exosomal microRNA-98-5p promotes cisplatin resistance in ovarian cancer by targeting CDKN1A. Cancer Cell Int. 2019;19(1):347. doi:10.1186/s12935-019-1051-3

119. Luo X, Wei J, Yang F-L, et al. Exosomal lncRNA HNF1A-AS1 affects cisplatin resistance in cervical cancer cells through regulating microRNA-34b/TUFT1 axis. Cancer Cell Int. 2019;19(1):323. doi:10.1186/s12935-019-1042-4

120. Han $\mathrm{D}$, Wang $\mathrm{K}$, Zhang $\mathrm{T}$, Gao GC, $\mathrm{Xu} \mathrm{H}$. Natural killer cell-derived exosome-entrapped paclitaxel can enhance its anti-tumor effect. Eur Rev Med Pharmacol Sci. 2020;24 (10):5703-5713. doi:10.26355/eurrev_202005_21362

121. Alvarez-Erviti L, Seow Y, Yin H, Betts C, Lakhal S, Wood MJA. Delivery of siRNA to the mouse brain by systemic injection of targeted exosomes. Nat Biotechnol. 2011;29(4):341-345. doi:10.1038/nbt.1807

122. Zahnd C, Wyler E, Schwenk JM, et al. A designed ankyrin repeat protein evolved to picomolar affinity to Her2. J Mol Biol. 2007;369 (4):1015-1028. doi:10.1016/j.jmb.2007.03.028 
123. Limoni SK, Moghadam MF, Moazzeni SM, Gomari H, Salimi F. Engineered Exosomes for Targeted Transfer of siRNA to HER2 Positive Breast Cancer Cells. Appl Biochem Biotechnol. 2019;187 (1):352-364. doi:10.1007/s12010-018-2813-4

124. Melzer C, Rehn V, Yang Y, Bähre H, von der Ohe J, Taxol-Loaded HR. MSC-Derived Exosomes Provide a Therapeutic Vehicle to Target Metastatic Breast Cancer and Other Carcinoma Cells. Cancers. 2019;11(6):798. doi:10.3390/cancers11060798

125. Kobayashi M, Sawada K, Miyamoto M, et al. Exploring the potential of engineered exosomes as delivery systems for tumor-suppressor microRNA replacement therapy in ovarian cancer. Biochem Biophys Res Commun. 2020;527(1):153-161. doi:10.1016/j.bbrc.2020.04.076

126. Liu H, Shen M, Zhao D, et al. The Effect of Triptolide-Loaded Exosomes on the Proliferation and Apoptosis of Human Ovarian Cancer SKOV3 Cells. Biomed Res Int. 2019;2019:2595801. doi:10.1155/2019/2595801

127. Kim SM, Yang Y, Oh SJ, Hong Y, Seo M, Jang M. Cancer-derived exosomes as a delivery platform of CRISPR/Cas9 confer cancer cell tropism-dependent targeting. $J$ Control Release. 2017;266:8-16. doi:10.1016/j.jconrel.2017.09.013

128. Zhang N, Wang Y, Liu H, Shen W. Extracellular vesicle encapsulated microRNA-320a inhibits endometrial cancer by suppression of the HIF1 $\alpha$ /VEGFA axis [published online ahead of print, 2020 May 27]. Exp Cell Res. 2020;394(2):112113. doi:10.1016/j. yexcr.2020.112113

129. Kooijmans SA, Vader P, van Dommelen SM, van Solinge WW, Schiffelers RM. Exosome mimetics: a novel class of drug delivery systems. Int J Nanomedicine. 2012;7:1525-1541. doi:10.2147/IJN. S29661

130. Lakhal S, Wood MJ. Exosome nanotechnology: an emerging paradigm shift in drug delivery: exploitation of exosome nanovesicles for systemic in vivo delivery of RNAi heralds new horizons for drug delivery across biological barriers. Bioessays. 2011;33 (10):737-741. doi:10.1002/bies.201100076

131. Zhao L, Gu C, Gan Y, Shao L, Chen H, Zhu H. Exosome-mediated siRNA delivery to suppress postoperative breast cancer metastasis. J Control Release. 2020;318:1-15. doi:10.1016/j.jconrel.2019.12.005

132. Tran PHL, Wang T, Yin W, et al. Development of a nanoamorphous exosomal delivery system as an effective biological platform for improved encapsulation of hydrophobic drugs. Int J Pharm. 2019;566:697-707. doi:10.1016/j.ijpharm.2019.06.028

133. Naseri Z, Oskuee RK, Jaafari MR, Forouzandeh Moghadam M. Exosome-mediated delivery of functionally active miRNA-142-3p inhibitor reduces tumorigenicity of breast cancer in vitro and in vivo. Int J Nanomedicine. 2018;13:7727-7747. doi:10.2147/IJN.S182384
134. Aqil F, Jeyabalan J, Agrawal AK, et al. Exosomal delivery of berry anthocyanidins for the management of ovarian cancer. Food Funct. 2017;8(11):4100-4107. doi:10.1039/c7fo00882a

135. Aqil F, Munagala R, Jeyabalan J, Agrawal AK, Gupta R. Exosomes for the Enhanced Tissue Bioavailability and Efficacy of Curcumin. AAPS J. 2017;19(6):1691-1702. doi:10.1208/ s12248-017-0154-9

136. Cheng Q, Shi X, Han M, Smbatyan G, Lenz HJ, Zhang Y. Reprogramming Exosomes as Nanoscale Controllers of Cellular Immunity. J Am Chem Soc. 2018;140(48):16413-16417. doi:10. 1021/jacs.8b10047

137. Wang QL, Zhuang X, Sriwastva MK, et al. Blood exosomes regulate the tissue distribution of grapefruit-derived nanovector via CD36 and IGFR1 pathways. Theranostics. 2018;8(18):4912-4924. doi: $10.7150 /$ thno. 27608

138. O'Brien KP, Khan S, Gilligan KE, et al.. Employing mesenchymal stem cells to support tumor-targeted delivery of extracellular vesicle (EV)-encapsulated microRNA-379. Oncogene. 2018;37 (16):2137-2149. doi:10.1038/s41388-017-0116-9

139. Ono M, Kosaka N, Tominaga N, et al.. Exosomes from bone marrow mesenchymal stem cells contain a microRNA that promotes dormancy in metastatic breast cancer cells. Sci Signal. 2014;7(332):ra63. doi:10.1126/scisignal.2005231

140. Kalimuthu S, Gangadaran P, Rajendran RL, et al.. Approach for Loading Anticancer Drugs Into Mesenchymal Stem Cell-Derived Exosome Mimetics for Cancer Therapy. Front Pharmacol. 2018;9:1116. doi:10.3389/fphar.2018.01116

141. Reza AMMT, Choi YJ, Yasuda H, Kim JH. Human adipose mesenchymal stem cell-derived exosomal-miRNAs are critical factors for inducing anti-proliferation signalling to A2780 and SKOV-3 ovarian cancer cells. Sci Rep. 2016;6:38498. doi:10.1038/srep38498

142. Li QL, Bu N, Yu YC, Hua W, Xin XY. Exvivo experiments of human ovarian cancer ascites-derived exosomes presented by dendritic cells derived from umbilical cord blood for immunotherapy treatment. Clin Med Oncol. 2008;2:461-467. doi:10.4137/cmo. s776

143. Bretz NP, Ridinger J, Rupp AK, et al.. Body fluid exosomes promote secretion of inflammatory cytokines in monocytic cells via Toll-like receptor signaling. $J$ Biol Chem. 2013;288 (51):36691-36702. doi:10.1074/jbc.M113.512806
OncoTargets and Therapy

\section{Publish your work in this journal}

OncoTargets and Therapy is an international, peer-reviewed, open access journal focusing on the pathological basis of all cancers, potential targets for therapy and treatment protocols employed to improve the management of cancer patients. The journal also focuses on the impact of management programs and new therapeutic agents and protocols on patient perspectives such as quality of life, adherence and satisfaction. The manuscript management system is completely online and includes a very quick and fair peer-review system, which is all easy to use. Visit http://www.dovepress.com/ testimonials.php to read real quotes from published authors. 